\title{
Factores generadores y propagadores de la crisis fiscal
}

\author{
José Antonio Alvarado
}

\section{Introducción}

El desequilibrio fiscal se ha convertido en uno de los mayores problemas de la economia salvadoreña y en un gran reto para la politica económica. Si bien la problemática presupuestaria ha sido molivo de varias investigaciones y continuadas discusiones, así como de algunos intenlos para enfrentarla mediante medidas de política económica, aún no se cuenta con una explicación adecuada de sus orígenes y dinámica, que nos permita entenderla en loda su dimensión y enirentar seriamente la conlinuada y cada vez más prolunda crisis fiscal, que a su paso agudiza los desequilibrios económicos y sociales, complejizándose en la dinámica global de la crisis estructural del modelo de acumulación capitalista salvadoreno.

Precisamente, para comprender adecuadamente la verdadera naluraleza y dinámica de la crisis fiscal hay que esludiar inmersa y como resultado "natural" de las características estruclurales y de la dinámica de funcionamiento y agolamienlo del modelo de acumulación de capilal en El Salvador; es indispensable identificar y analizar las raices eslruclurales del desequilibrio presupuestario, la dinámica de la crisis y los actores que la aceleran y propagan. Indudablemente esta es una larea muy compleja,que involucra el análisis de la formación económico-social en su conjunto de su desarrollo histórico.

En este trabajo no prelendemos agotar análisis de la problemálica presupueslaria, pero tratamos de aportar una explicación más realista e integral de la naturaleza y dinámica de la crisis liscal en nuestro pais, identificando y analizando los factores (estructurales) y propagadores del desequilibrio presupuestario, en el marco del proceso global de acumulación y valorización del capital. La hipótesis central que guia el análisis es la siguiente: "La crisis fiscal en El Salvador es de naturaleza estruc- 
tural. Las características estructurales y la dinámica de funcionamienlo del modelo han condicionado y definido los faclores generadores del desequilibrio fiscal, que entra en un dinámica expansiva y "explosiva" en la medida que se profundizan los obstáculos y el agolamiento económico y politico del modelo de acumulación de capital".

En la primera parte de este trabajo, a manera de anlecedentes, se exponen las ideas básicas de la dinámica y crisis del modelo oligárquico exportador tradicional, el papel del Estado y los reacomodos institucionales; se esludia el impacto que todo ello ocasiona sobre las finanzas públicas. El periódo de análisis comprende desde tinales del siglo pasado hasta mediados de la década del cuarenta del siglo actual.

Seguidamenle se analiza la naturaleza y dinámica de la producción fabril en El Salvador desde finales de la década del cuarenta, y cómo los requerimientos del tipo de industrialización impulsado en nuestro pais condiconan y definen los factores generadores de la crisis fiscal, que entran en una dinámica expansiva $\theta$ irreversible en la medida que se intensitica la concentración, centralización y transnacionalización del capital y que se profundizan los desequilibrios y rigideces estructurales, volviéndose transparente el agotamienlo del modelo. Se analiza esta dinámica hasta finales de la década del setenta.

En la tercera parte del trabajo, se identifican y analizan los lactores propagadores de la crisis tiscal, derivados de los requerimientos de la guerra y de la valorización del capital, que no sólo aceleran el desequilibrio presupuestario, sino que profundizan la naturaleza regresiva, injusta y rlgida del tinanciamiento público, imprimiéndole un carácter "explosivo" a la crisis. Se estudia el agotamiento fiscal en la década de los ochenta, los "paquelazos" fiscales y los limites económicos y políticos de la dinámica presupuestaria.

No eslá demás senalar que aunque el propósito de este estudio es aportar una explicación realista e integral de la naturaleza y dimensión del problema presupuestario en El Salvador, ciertamente adolece de vacios y debilidades que escapan a la voluntad del autor. El involucramiento de factores económicos, sociales y politicos y de su desarrllo histórico, complejizan sobremanera el análisis. Sin embargo, el estudio de algunos de estos factores y más que todo, el análisis delallado de la naturaleza, dinámica y crisis de las tinanzas públicas a lo largo de esle siglo, constituye el aporte principal de este trabajo que podría servir de base para una explicación más adecuada de la crisis fiscal en EI Salvador.

\section{Antecedentes}

Como en toda economla capitalista, el modo de producción capitalista en El Salvador "ha plasmado un Eslado que corresponde a él", adecua- 
do a sus caracteristicas dependientes y oligárquicas. El desarrollo y crisis de este modo de producción ha ido requiriendo una mayor complejzación y dimensión de la participación del Estado, a manera de coadyuvar esfuerzos para inserción y reproducción de un modelo de sociedad que desde muy temprano se caracterizarla por su extrema desigualdad y un creciente somelimiento a los intereses hegemónicos del capitalismo mundial.

La subordinación del Estado a los intereses del proceso de valorización y acumulación de capital, no sólo se ha producido a expensas de una creciente marginación de amplios sectores de la población, lambién ha ido tensionando peligrosamente los desequilibrios estructurales y mostrando, cada vez más elocuentemente, los límites y crisis del modelo y de la misma actuación del eslado para salvaguardarlo.

\subsection{La creación de las condlclones para la acumulación del capltal agro-exportador}

El estado salvadoreno no se puede comprender aisladamente del carácler oligárquico y dependienle que ha marcado el desarrollo del capitalismo en El Salvador. El estado-nación surge asumiendo su papel como responsable de la creación de las condiciones materiales generales para la acumulación del capital agro-exportador, que mediante la producción de calé se convertla en el mecanismo fundametal de inserción al mercado capitalista mundial que se transformaba en imperialismo.

Efectivamente, las medidas más destacadas de la actuación del Estado durante la segunda milad del siglo XIX, fueron aquellas orientadas a posibilitar la acumulación de capital en la agricultura, mediante la creación del andamiaje juridico y la intraestructura básica requeridas por la explotación catetalera. A pesar de la resistencia de los habitantes de las lierras ejidales y comunales, el proceso de apropiación privada y concentración de la tierra requerido por el cultivo de café, se consolida y "legaliza" mediante tres medidas fundamentales que marcan el nacimiento de la República Liberal: la Ley de Extinción de Ejidos de 1882, la Constitución Polftica de 1886 y la Ley de Extinción de Comunidades en Abril de 1891; asl, se destrulan las aladuras que imposibilitaban el irrestriclo cambio de propiedad y se garantizaba jurídicamente una nueva estructura y lógica de funcionamiento en la que el interés privado y la acumulación de capital serlan los pilares del nuevo sistema. La separación de sus medios lundamentales de vida de que fueron objeto los pobladores de tierras comunales y ejidales, aunado a la creación de leyes y aparalos policiales adecuados ${ }^{1}$, garantizaban la provisión de la mano de obra demandada por la explotación caletalera. La continuación y agilización del proceso de concentración de la propiedad de la lierra y del capilal dedicado a esla actividad, se vio favorecido también por el Código Civil y el sistema de crédilo 
vigente que permitian, la confiscación de propiedades hipolecadas en caso incumplimiento, por lo que muchos pequenos y medianos produclores cedieron sus derechos a los grandes cafetaleros y banqueros.

Ciertamente, la expansión catetalera se caracterizó por la rápida integración vertical y centralización del capital de la induslria; desde principios del sigo XX algunos grandes cafelaleros controlaban también el beneficiado y la exportación del grano, asi como los bancos creados en el país para ejercer un mayor conlrol de la industria caletalera. Asl se define tempranamente el carácler oligárquico de la acumulación agro-exportadora. Efeclivamente, la "élite económica" de principios de los anos veinte estaba constituida por 66 familias ligadas a la producción, beneficiado y exportación de café, y a la banca; destacándose desde entonces como los más prominentes, algunos nombres como Bloom, Canessa, Hill, Alvarez, De Sola, Guirola y Deininger 2.

La inversión extranjera, incialmente inglesa y luego de procedencia norteamericana, fundamenlalmente orienlada a transporte y comunicaciones, resultaba complementaria para la producción cafelalera facilitando su realización.

Toda esla conjugación de lactores y condiciones que se presentaron desde finales del siglo $X I X$ hasta la primera cuarta parte del sigo $X X$, consolidaron a la producción agro-exportadora como la principal fuenle de acumulación de capital, definiendo los valores y la lógica de luncionamiento de la economia. Sin embargo, el carácter oligárquico y marginador, y la extrema dependencia del mercado mundial, desembocarian rápidamente en la primera gran crisis del modelo agro-exportador, que daría paso a una nueva elapa caracterizada por el abandono de los principios liberales tradicionales en favor de la ampliación y redefinición de la actuación del Estado, en la que éste debería asumir más directamenle la salvaguardia de los inlereses del capital agro-exportador, tanto en cuanto a los requerimientos económicos como proporcionando la "estabilidad social" y "legitimación" requerida para la preservación de la fuente fundamental de acumulación.

\subsection{La crisis del modelo ollgarquico exportador tradiclonal}

El carácter extrovertido del modelo, la ausencia de control sobre los precios internacionales del calé y el acelerado proceso de concentración y centralización del capital, condujo al emprobrecimiento masivo de amplios sectores de la población y a un creciente descontento popular; mientras al interior de la industria cafetalera se agravan las contradicciones entre sus componentes oligárquicos y los demás participantes que tenian sus intereses exclusivamenle en el cullivo del grano. El agravamiento de estas tensiones se potencia y alcaza su climax con la 
fuerte caida de los precios internacionales del calé en 1929-1930, que se resuelve trasladando el peso de la crisis sobre los sectores populares y redefiniendo la acumulación del Estado en función de los nuevos y mayores requerimientos de la acumulación agroexportadora.

\section{a) Sintomas de la Crisis (1920-1929)}

Aunque ya desde linales del siglo XIX el café generaba más del $80 \%$ de los ingresos de exportación perfilándose como la principal actividad económica del país, no es sino hasta en la década de los anos veinte del siglo actual que se consolida como la fuente fundamental de acumulación de capital. La caída de los precios internacionales del café a raíz de la primera guerra mundial ${ }^{3}$, coadyuvó a una mayor concentración y centralización del capital,en la medida que muchos propietarios se vieron obligados a ceder sus derechos a unos pocos grandes productores, beneficiadores y banqueros, que fortalecla su poder.

Esta consolidación de la "economía cafatalera" se produjo a expensas del empobrecimiento masivo de la población. Además de la expropiación de sus medios de vida de que fueron objeto los trabajadores rurales, que también se veian obligados a aceplar salarios miserables, la expansión caletalera produjo un desplazamiento creciente de los cultivos básicos de la población y una fuerte corriente migratoria desde las áreas rurales empobrecidas hacia las ciudades y otras regiones del área, principalmenle la cosla norte de Honduras. Entre 1922 y 1926 el precio del arroz aumento $300 \%$, el de los frijoles $225 \%$ y el maiz $100 \% 4$; el desplazamiento de trabajadores rurales hacia las zonas urbanas agudizo la compelencia por los puestos de trabajo disponibles en la ciudad, que aunado al encarecimiento de los produclores básicos, expandia el descontento popular.

La masificación y profundización de la pobreza derivada de la expansión caletalera, se traduciría en el desarrollo y ampliación de un fuerte movimiento popular que desde los primeros anos de la década de los veinte aglutinaba a campesinos, jornaleros, artesanos y otros grupos de trabajores y empleados urbanos: un lenómeno que para ese entonces resullaba único en Centroamérica. El creciente fortalecimiento y agilación del movimiento popular agudizaba también la situación linanciera del Estado en la medida que se demandaba mayor cantidad de empleos y servicios para los grupos urbanos, al mismo liempo que se cuestionaba la legitimidad del Estado y del Slatus quo, conviertiéndose en un poderoso factor de deseslabilización.

Por otro lado, la concentración y centralización del capital generaba contradicciones adicionales al interior del grupo dominante, diferenciándose tres fracciones: los beneficiadores y exportadores de café y a 
su vez grandes productores y banqueros (fracclón ollgárquica); los que tenlan sus intereses casi exclusivamente en el cultivo del grano; y una burguesla industrial incipiente que vela en la producclón manufacturera y en el acelerado proceso de ubanización una fuente altemativa de valorización del capilal.

El control sobre el beneficiado y exportación de café, asl como el monopolio de la banca, garantizaba ganancias extraordinarias a la tracclon oligárquica que compraba el café a un preclo promedio de $\$ 0.06-\$ 0.10$ y lo vendian FOB a $\$ 0.20$ - \$0.26 por libra, apropiándese de gran parte de los excedentes generados en la industrla. El fortalecimlento económico de este grupo era muy evidente: entre 1922 y 1930, el valor eslimado de los mayores beneficios de calé se duplico, aumentando de $\$ 1,228,000$ a $\$ 2,907,000$ entre esos anos; el $53 \%$ del valor de estos beneficios era controlado por los cinco mayores productores. En esos mismos anos, el valor conjunto de las viviendas de la "elite" aumentó de $₫ 1,800,000$ a $\$ 9,000.000$, además de poseer los edíticlos comerclales de San Salvadors.

\section{b. El estallido de la crisls y la redifleación del apartado estatal}

La alta polarización de la sociedad en extremos de pobreza y riqueza era muy evidente en los primeros anos de la década de los veinte. El afloramiento y agudizamiento del conjunto de contradicciones surgidas del proceso de concentración y centralización del capital agro-exportador, y la creciente organización la lucha sindical y polltica de los sectores marginados y menos favorecidos, posibilito un breve experimento democrático en El Salvador que se inicia con la administración de Plo Romero Bosque en la segunda mitad de la década de los veinte y termina con el derrocamiento de Arturo Araujo en 1931, cuyo gobierno representaba el más serio intento de la débil fracción modemizante del capital por imponer su proyecto6.

La fuerte cáida de los precios intemacionales del caté al arribar la década de los treinta, aunado a la crecienle masiticaión y radicalización del movimiento popular, trascendla los IImites del intento modemizante imposiblitaba el continuar manteniendo $\theta$ impulsando reformas economicas y políticas. La gravedad y peligrosidad de la crlsis requerla salvaguadar la fuente fundamental de acumulación, la producción y exportación de café, subordinándose a ella cualquier otro Interés de capitales particulares.

La prolección de los intereses agroexportadores sólo podla lograrse trasladando los efectos de la crisis sobre las mayorlas empobrecidas del país y olvidándose de los intentos reformislas; para esto era imprecindible un reacomodamiento de la actuación del Estado, cuyas funcio- 
nes se amplian y complejizan. La Ley Moraloria, la devaluación del colón y la regulación de la circulación monetaria, aunadas a la represión contra el movimiento popular, rescataron y garantizaron la hegemonia de los intereses agro-exportadores.

Efectivamente, la preservación de la fuenle fundamental de acumulación de capital y su lógica de funcionamiento, requería un aparato estatal más complejo e "inlervencionista"; los principios liberales tradicionales ya no resultaban funcionales ante las nuevas y mayores necesidades del proceso de acumulación. El Eslado debia asumir un papel más activo y decidido para la creación de las condiciones materiales de la producción, para mediar entre los intereses de capilales particulares y garantizar la hegemonla de la fracción lundamental, asi como para reprimir y desarticular el movimiento popular; esto sólo podia lograrse con una férrea dictadura militar de carácter fascita, que se inicia con el gobiemo del general Maximiliano Hemández Martinez.

Las medidas económicas adoptadas por la administración de Hernández Martinez que se mantienen en el poder hasta 1944, reflejan claramente la atención prioritaria de que fueron objeto los intereses fundamentales del capital en EI Salvador. Las medidas monetarias y crediticias se oriemlaron a mantener o aliviar la reducción de los ingresos del sector agroexportador. Por olro lado, reconociendo que la acumulación industrial generaba la destrucción de la produccción artesanal y la expansión del desempleo y del desconteto popular, además de que su expansión requerla de reformas económicas que posibiltaron una ampliación del mercado lo que atentaba contra los intereses de la fracción oligárquica, se adoptan medidadas anti-industrializantes que frenan las aspiraciones de la tracción modernizanle del capilal, coadyuvando a relardar el proceso de industrialización en nuestro país.

\section{Las Ananzas Públlcas (1900-1944)}

El carácter oligárquico y dependiente del modelo que se había desarrollado y entrado en crisis durante este peridodo, se reflejaba también sobre la estructura y dinámica de las linanzas públicas; la orientación del gasto público y la estructura tributaria reflejaban y agudizaban ese carácter marginador y dependiente del modelo. La creación por parte del Eslado de las condiciones materiales que posibilitaron la acumulación agro-exportadora, mediante la provisión de la infraestructura básica y los servicios administrativos y policiales requeridos, se reflejan en un gasto público creciente cuyo monto se triplica en las primeras tres décadas de este siglo, destinándose más del $90 \%$ de esos recursos a 4 rubros fundamentales: administración general, Delensa, Servicio de la deuda pública y fomento económico (ver cuadro $N^{2}$.1), necesarios para posibilitar la acumulación oligárquica; ciertamente, algunos grupos de empleados y 
trabajadores urbanos lograban algunos beneficios si podian insertarse dentro de la creciente burocracia estatal.

Es importante deslacar la creciente importancia de las actvidades "fomento económico" emprendidas por el Eslado, más directamente ligadas a la creación de las economías externas requeridas por la acumulación oligárquica; las asignaciones de eslas aclividades más de cuatro veces entre 1900 y 1939, resultando notoria la mayor participación de estas actividades al instaurarse la dictadura de Hernández Martínez; entre 1930 y 1939 , los recursos asignados a fomento económico aumentan de menos del $14 \%$ a $20 \%$ del gaslo público total.

Mientras el gasto público atendia prioritariamente las necesidades del proceso de acumulación de capital, su financiamiento descansaba sobre los sectores de pequenos y medianos ingresos y sobre el comercio exterior. Desde finales del siglo pasado y hasta la primera mital del siglo XX, la fuente fundamental de ingresos tributarios lo conslituyó el gravamen sobre las imporlaciones, que aportó más de $50 \%$ de las recaudaciones impositivas durante ese periodo; el gravamen sobre las exportaciones de café solo alcanzo una participación promedio del $15 \%$ de las recaudaciones Iributarias hasta principios de la década del cuarenta (ver cuadro $N^{0}$ 2) lo que obedecia a la politica de incentivos fiscales para fomentar la industria cafelalera. Ciertamente, si bien los cafalaleros no pagaban más que 70 centavos por cada saco de $100 \mathrm{Kgs}$. de calé exportado y hasla 1915 tampoco pagaban impuestos sobre la renta y el patrimonio porque dichos impuestos aún no existian, gran parte del gravamen sobre las importaciones recaía sobre este sector ya que ellos detentaban la capacidad para importar.

No obslante la excesiva bondad con que son tratados los caletaleros al pagar un impuesto muy reducido sobre la exportación del grano, además de la ausencia de tributación directa y aún cuando ésta es creada a partir de 1915 y hasta principios de los años treinta no logran aportar más de un $6 \%$ del total de ingresos tributarios, lodo ello aunado a la orientación del gasto público, llegó a definir desde principios del siglo el carácter injusto, oligárquico y dependiente de las finanzas públicas en El Salvador.

Después de las recaudaciones sobre el comercio exterior que en la segunda mitad de la década de los veinle participaron con más del $70 \%$ de los ingresos fiscales, el segundo lugar lo ocupaban los gravámenes parte de los ingresos tributarios durante las tres primeras décadas (ver cuadro $\mathrm{N}^{*} 2$ ). Es decir, los seclores de pequefos y medianos ingresos soportaban una gran parte de la carga tributaria, mienlras eran excluídos de los beneficios del gaslo públicos; efectivamente, los gastos en servicios culturales y sociales que podrán considerarse directamente ligados al bienestar social, luvieron una participación promedio inferior al 


\section{CUADRO $N^{2} 1$ \\ Estructura del Gasto Público (1900-1943) \\ En miles de colones y porcentajes)}

\begin{tabular}{|l|r|r|r|r|r|r|r|r|r|r|}
\hline & \multicolumn{2}{|c|}{$1900-1904$} & \multicolumn{2}{c|}{$1915-1919$} & \multicolumn{2}{|c|}{$1924-25 / 1928-29$} & \multicolumn{2}{l|}{$1934-35 / 1938-39$} & \multicolumn{1}{c|}{$1939-43$} \\
\hline \multicolumn{1}{|c|}{ TOTAL } & $7,725.3$ & 100.0 & $12,754.6$ & 100.0 & $23,903.2$ & 100.0 & $21,178.7$ & 100.0 & $22,061.6$ & 100.0 \\
Administración General & $1,445.9$ & 18.7 & $4,704.1$ & 36.9 & $6,943.1$ & 29.0 & $7,760.8$ & 36.6 & $8,875.9$ & 40.2 \\
Defensa Nacional & $1,654.8$ & 21.4 & $3,040.6$ & 23.8 & $4,379.0$ & 18.3 & $3,679.2$ & 17.4 & $3,623.4$ & 16.4 \\
Servicio de la Deuda Pública & $3,089.3$ & 39.9 & $1,817.3$ & 14.2 & $6,467.9$ & 27.1 & $2,660.8$ & 12.6 & $1,136.3$ & 5.2 \\
Fornento Económico & 991.1 & 12.8 & $1,377.0$ & 10.8 & $3,325.6$ & 13.9 & $4,033.1$ & 19.0 & $4,424.5$ & 20.1 \\
Servicios Cullurales y Social. & 559.0 & 7.1 & $1,815.5$ & 14.2 & $2,767.6$ & 11.6 & $3,044.8$ & 14.4 & $4,001.5$ & 18.1 \\
\hline
\end{tabular}

Fuenle: Wallich y Ader. "Proyecciones económicas de las finanzas públicas, un estudio experimental en EI Salvador. México, FCE, 1949. Cuadro № 17. 
$15 \%$ del presupueslo nacional. No es sino hasla linales de la década del cuarenta, como resultado de la "nueva" extrategia de crecimiento que se impulsarian en la años subsiguientes (industrialización), que los gastos en servicios sociales y cullurales llegan a constituir un rubro importante dentro de las asignaciones presupueslarias del Eslado.

La extremada e insegura dependecia de la economía y de las finanzas públicas al sector exlerno, condujo a la primera gran crisis financiera del Estado en la década de los treinia. Por un lado, la pesada carga de la deuda pública, gran parte de ella conlratada para tinanciar la construcción de infraestructura básica y proveniente de luenles externa, absorbia más de la cuarta parte del presupuesto nacional (cuadro No. 1). Por otro lado, la caida de los precios internacionales del café, en la media que se restringió la capacidad para imporlar, se tradujo en la contracción de un $50 \%$ de los ingresos provenientes del gravamen sobre las importaciones durante la década de los treinta (cuadro No. 2), conduciendo a una grave crisis linanciera la que, a pesar de algunas relormas fiscales implementadas por la dictadura de Hernández Martinez, se mantuvo hasla el final de la segunda guerra mundial; efeclivamente, los $₫ 20$ millones de ingresos tributarios que se oblenian a finales de los años veinte, no volvieron a lograrse sino hasta mediados de la década del cuarenta, cuando finalizaba la guerra se recuperan los precios inlernacionales del café, posibililando que las recaudaciones de los gravámenes sobre el comercio exterior aumenla más de cinco veces, de $₫ 5.7$ millones en 1936 a $₫ 31.7$ millones en 1947 .

Entre las reformas fiscales implementadas por Hernández Martínez para paliar la crisis linanciera del gobierno, sobresalen la cancelación de la deuda pública cuya participación en el presupuesto nacional se reduce de un $27 \%$ a finales de los años veinte, a un $5 \%$ en 1939-43 (cuadro № 1).Si bien esla medida aparenlemente resullaba positiva y era presentada como una manifestación de carácler "nacionalista" de la dictadura, la cancelación de la deuda se produjo del presupuesto público. Efectivamenle, entre las otras reformas fiscales implementadas por el gobierno de Hernández Marlinez, se destacan la disminución general de los salarios de los empleados públicos decrelada por el régimen y el aumento de la tributación regresiva. Las recaudaciones de los impuestos sobre el consumo interno y transacciones aumentaron más de dos veces durante la dicladura., de $\$ 3.3$ millones en los inicios de los anos treinta a $\$ 7.9$ millones en 1944.

Ciertamente, la triburación directa también aumenló su participación y se crearon nuevos gravámenes, pero en ningún momento durante el gobierno de Hernández Martinez y hasta linales de la década del cuarenta, la Iributación directa logró superar las recaudaciones de los gravámenes indirectos inlernos; asi, en 1944 los ingresos provenientes 


\section{CUADRO N²}

Estructura Irlbutarla (1900-1944)

En mlles de colones y porcentajes

\begin{tabular}{|c|c|c|c|c|c|c|c|c|c|c|c|c|}
\hline \multirow[b]{2}{*}{$\begin{array}{l}\text { Ingresos Tributarios } \\
\text { Totales }\end{array}$} & \multicolumn{2}{|c|}{$1900-1903$} & \multicolumn{2}{|c|}{$1915-1919$} & \multicolumn{2}{|c|}{$1925-1929$} & \multicolumn{2}{|c|}{$1930-1933$} & \multicolumn{2}{|c|}{1939} & \multicolumn{2}{|c|}{1944} \\
\hline & $6,393.8$ & 100.0 & $10,385.1$ & 100.0 & $19,619.6$ & 100.0 & $16,775.8$ & 100.0 & 8.799.3 & 100.0 & $25,889.1$ & 100.0 \\
\hline 1. Impuestes Directos & - & - & 477.0 & 4.6 & 802.9 & 4.1 & $1.235 . \theta$ & 7.4 & 646.0 & 7.3 & $3,340.8$ & 12.9 \\
\hline $\begin{array}{l}\text { 2. Impuestos Indirec. } \\
\text { 2.1. Impuestos sobre }\end{array}$ & $6,393.8$ & 100.0 & $9,908.1$ & 95.4 & $18,816.7$ & 95.9 & $15,540.0$ & 92.6 & $7,877.7$ & 92.6 & $22,068.4$ & 87.1 \\
\hline Comercio Exterior & $4,372.3$ & 68.4 & $6,787.8$ & 65.4 & $14,092.0$ & 71.8 & $12,169.5$ & 72.5 & $5,727.0$ & 65.1 & $14,143.5$ & 54.6 \\
\hline a) S/mportaciones & $3,761,3$ & 58.5 & $4,828.3$ & 46.5 & $11,631.2$ & 59.3 & $0,854.8$ & 52.8 & $5,518.4$ & 62.7 & $9,719.8$ & 37.5 \\
\hline $\begin{array}{l}\text { b) SIExportaciones } \\
\text { 2.2. Impuestos Ind- } \\
\text { reclos Internos }\end{array}$ & 611.0 & 9.6 & $1,959.5$ & 18.9 & 2.460 .8 & 12.5 & $3,314.7$ & 19.8 & 208.6 & 2.4 & $4,423.7$ & 17.1 \\
\hline $\begin{array}{l}\text { a) SIConsum. Produc. } \\
\text { b) SAAclos Juridic. y }\end{array}$ & $1,913.6$ & 29.9 & $2,662.4$ & 25.6 & $4,093.6$ & 20.9 & 2.799 .4 & 16.7 & 1,$697 ; 7$ & 19.3 & $6,414.3$ & 24.8 \\
\hline transacciones & 107.9 & 1.7 & 457.9 & 4.4 & 631.1 & 3.2 & 572.1 & 3.4 & 453.0 & 5.2 & $1,510.6$ & 5.8 \\
\hline c) Otros Impuestos & - & - & - & - & - & - & - & - & 275.6 & 3.1 & 479.9 & 1.8 \\
\hline
\end{tabular}

Fuente: Wallich y Ader. Op. Cit

岕 
del consumo interno y transacciones duplicaban al conjunto de recaudaciones provenientes de la tributación directa (cuadro No. 2).

\section{Factores generadores de la crisls flscal}

La experiencia de los afnos treinla habla mostrado por primera vez y en toda su dimensión las graves implicaciones y debilidades del modelo oligárquico agro-exporlador. La crisis logró paliarse descargando sus efectos sobre los sectores menos favorecidos, mediante un aparato estatal más complejo e "intervencionista" y que desde entonces asumiría la forma de lérrea dictadura militar de carácter fascista.

Las funciones y acciones asumidas por el régimen de Hernández Martínez se orientaron en todo momenlo a salvaguardar los intereses de la oligarquía agro-exportadora, marginando a la fracción modemizante del capítal. Como senaláramos anles, además de reprimir a los sectores populares y marginartos de cualquier participación en la dirección y beneficios del aparalo estalal, el régimen militar osbtaculizo $\theta$ impidió también el fortalecimiento de la fracción industrializante del capilal; inicialmente se decrela una ley que prohibe la importación de maquinaria para los ingenios azucareros y los beneficios algodoneros; posteriormente, en 1939 , se prohibe el establecimiento de fábricas con un capital superior a $\$ 20,000$ y que dedique a la produccion de calzado, ladrillos, jabones, artículos de hojas de metal o de zinc, y otros. A excepción de la induslria textil, la implementación de estas medidas, anti-industrializantes por el régimen de Hemández Martínez, frena el surgimienlo de la industria en EI Salvador. Sin embargo, esa actitud relrógrada no durarla mucho ya que atentaba contra los mismos intereses del gran capital.

Por otro lado, si bien durante la administración de Hemández Martlnez, se logró superar la mayor gravedad de la crisis, la contracción económica se mantuvo durante loda la década de los anos treinta hasta la primera mitad del cuarenta. Eleclivamente, el valor de las exportaciones de café cayó de un nivel de $\$ 35.5$ millones en los anos veinte hasta un promedio de $\$ 23.3$ millones en la siguiente década ${ }^{7}$, manteniéndose a ese nivel hata el final de la segunda guerra mundial. La prolongada recesión económica y los reacomodos del capitalismo mundial en la postguerra, exigian la búsqueda de fuentes alternativas de acumulación del capital. El alza sostenida de los precios internacionales del café entre 1945 y 1954, posibilitó los recursos necesarios para impulsar esa fuente alternativa de acumulación. Eectivamente, la conjunción de todos estos factores y condiciones, condujo a una alianza táctica entre las principales Iracciones del capital local y mundial para el impulso de la industrialización. en el marco de un nuevo relanzamiento del proceso de acumulación nacional y mundial; obviamente, lodo ello requeria de la readecuaclón del aparato estalal, que asumiria nuevas y más complejas funciones. 


\section{Naturaleza y IImites el proceso de Industrlallzaclón}

La acumulación industrial en El Salvador adquiere importancia sólo a partir de 1945, destacándose cualro lactores lundamentales que la posibilitaron: "la reserva de mercado" para algunos productos manufactureros de consumo final derivada de la conlinuación de las dificultades para obtener bienes importados, que se prolongó durante loda la década de los treinta hasla el perlodo de posl-guerra; el auge de la agroexporlación derivado de la recuperación del mercado mundial; la transnacionalización del capital impulsada por el nuevo centro hegemónico del capitalismo mundial, Estados Unidos; y el nuevo papel desempenando por El Estado, principalmente a ralz del golpe militar de diciembre de 1948.

El aumento de los precios internacionales del café en la post-guerra, generó los excedentes requeridos para impulsar la acumulación industrial, que en esla primera etapa se nutriria de la demanda insatisfecha de algunos productos manulaclurados importantes y de olros bienes que se producian artesanalmente, asi como una creciente demanda adicional derivada de la continuada expansión de las funciones y acciones del Estado.

La expansión económica mundial de la post-guerra se tradujo en la bonanza de los precios internacionales del cale, que aumentan de un indice de 100 en 1945 (\$14.9/qq) a 457 en 1954 (\$68/qq),8, generando excedentes que trascienden los límites de la agro-exportación como fuenle de valorización. La expansión de la acumulación caletalera se enfrentaba a límites derivados del mercado mundial y de la ausencia de tieras adicionales aptas para un cultivo rentable. Los cuanliosos excedentes generados por el auge de la agro-exportación requeria de una fuente complementaria de valorización, que posibilitará la continuación del proceso de acumulación de capital.

La expansión de la producción algodonera también conlribuyó a la generación de excedentes y al impulso de la industria textil que se constituyó en una de las más prósperas; el valor de las exportaciones de algodón se multiplica por 10 entre 1945 y $1950^{9}$. La construcción de la Carretera del Litoral, que se inicia en 1952, contribuyó a la expansión algodonera habilitando tierras adicionales a lo largo de la costa salvadorefia principalmente en la región oriental, tierras que hasla enlonces habian sido margindas por su aislamiento y por no ser aplas al cultivo del café. La producción algodonera ofrece un nuevo campo para la acumulación capitalisla y para la introducción de algunos elementos modernizantes mediante la mecanización de algunas tareas requeridas por el cullivo.

La presencia de todos estos elementos, aunado a los nuevos requerimientos para el relanzamienlo del capitalismo mundial, con su nuevo eje de Estados Unidos, conducen a delinir e impulsar a la industria manufac- 
turera como una fuente complementaria de acumulación de capital. Electivamente, la nueva elapa de desarrollo de la acumulación capilalisla mundial, requeria industrializar la periferia, especíticamenle con manufacturas "ligeras" que posibilitaran la expansión del capital transnacional, principalmente de procedencia norteamericana; las necesidades de esle capital enconiraron eco en la burgueria nacional, acordando de hecho la implementación de las medidas que posibilitaran las condiciones requeridas para la expansión industrial. Se hace necesario un Estado más "intervencionista", que sin descuidar la fuente fundamental de acumulación que continuaría siendo la agro-exportación, se hiciera cargo lambién de crear y mantener las condiciones para el desarrollo industrial que se convertiria en una nueva fuente de acumulación de capital.

Como veremos más adelanle, la hegemonia de los inlereses oligárquicos y los requerimienlos del capital mundial, conducirán a definir un proceso de industrialización fuertemente subsidiado por el Estado, que agudizará los desequilibrios eslruclurales y alianzará la dependencial del nuevo centro hegemónico del capitalismo mundial.

\section{a) El papel del estado en el proceso Industrlallzaclón (1948- 1960)}

Para comprender adecuadamente la dimensión y trascendencia de las nuevas funciones y actuaciones del Estado, debemos definir la naturaleza y límites del proceso de induslrialización que se impulsaria.

En este sentido habría que deslacar la naturaleza oligárquica del proceso. Los recursos que se invertirian en la producción industrial provendrian de los excedentes generados por el capital agro-exportador en la post-guerra; es decir, la industrialización ofrece una nueva fuente de valorización para el capital oligárquico, posibililándole el control del proceso. La posición hegemónica de los intereses agro-exportadores le permitirá sefnalar los límites al proceso de industrialización; éste deberá desarrollarse sin romper las condiciones que garanlizan la reproducción del capital agro-exportador, es decir, deberá realizarse sin allerar la esiructura de propiedad ni la distribución del ingreso existente. Efectivamente, la naluraleza oligárquica del proceso de industrialización le impulso limites muy estrechos para la expansión de esla nueva fuente de acumulación de capital; estos límites se reflejan en: la estrechez del mercado interno; la "especialización" en la producción de manulacluras de consumo final; la poca capacidad para general empleo; la extrema dependencia de insumos y maquinaria importada, y la ausencia de una dinámica propia y autosostenida.

Desde sus inicio, la acumulación industrial en El Salvador presentaba estas limitaciones. Precisamente la actuación del Eslado se vuelve más necesaria para Iratar de paliar las debilidades del proceso, tanto para gene- 
rar demanda adicional como para crear las condiciones legales y materiales que garanticen una inversión industrial rentable; anle la estrechez del mercado interno, el Estado deberia asumir lambién la responsabilidad de asegurarle mercados externos e implementar las medidas de política económica requerimientos para mejorar la competitividad de la industria local. Es decir, el Estado se convierte en un factor clave para el surgimiento y desarrollo de la acumulación industrial; con su participación trataria de subsanar los electos negativos y las limitaciones derivados del carácler oligárquico de la industrialización en nuestro pais.

El equipo de gobierno que asume el poder con el golpe militar en 1948, sienta las bases para esta redifinición del papel del Estado; se adoplan las medidas y acciones lundamentales para la expansion industrial. Entre las medidas más importantes, están: la abolición de las leyes que restringian la mecanización; la abolición de toda forma de cancelación de salarios en especie; la creación de economías exlernas medianle la construcción de carreleras, presas hidroeléctricas y la dolación de la mano de obra en cantidad y la calidad requeridas; el otorgamiento de incentivos a la inversión induslrial mediante la dispensa de diferentes impuestos y la canalización de créditos subsidiados; la firma de Iratados de libre comercio con otros países de la región y la adopción de medidas de política económica que garantizarian la competitividad y una "reserva de mercado" para la industria local. ${ }^{10}$

A pesar del amplio y creciente apoyo del Eslado, la expansión indusIrial mostraba sus límites a tinales de la década del cincuenta, derivados fundamentaimente del agolamiento del escaso mercado interno y de la fuerte caida de los precios internacionales del calé en los últimos anos de la década; lomando como base el año de 1953, los precios del café descienden de un indice de 125 en 1954 a 74 en 1959.11 La contracción de los excedentes de la agro-exportación que nutria a la acumulación indus. trial, la saturación del mercado inlerno y las dificullades tecnológicas que limitaban el aprovechamiento renlable de algunos mercados externos principalmente regionales, conducieron a la primera recesión industrial a finales de la década del cincuenta.

La siguiente década se caracterizaria por un nuevo intento para el relanzamiento induslrial en El Salvador; los límiles que entrentaba el proceso tralarian de ampliarse mediante la integración económica regional, una alianza más estrecha con el capilal transnacional principalmente de procedencia norteamericana, y mediante una continuada y cada vez más amplia participación estalal benefactora de la acumulación industrial.

\section{b. Los gérmenes de la crisls flscal}

Como hemos senalado, las debilidades y limilaciones de la industrialización requiere de nuevos y más complejas acciones del Eslado; este 
mayor "intervencionismo" estatal, se manifiesta en la expansión y recomposición del presupuesto público. Electivamente, el manejo de las finanzas públicas juega un papel fundamental en el proceso de industralización y son los requerimientos de este proceso los que se encargarán de definir los faclores generadores de la crisis fiscal, que se vuelve transparenle en la década del setenta.

El gasto público resultó fundamental para la generación de demanda adicional y la creación de la infraestructura básica. Entre los primeros anos de la década del cuarenla hasta inicios del cincuenta, el monto del presupuesto público aumentó más de cinco veces, orientado fundamentalmente a la creación de la infraestructura básica y la prestación de algunos servicios públicos que se volvian más necesarios para la expansión industrial y la creciente urbanización; los gastos sociales en materia de educación, salud y otros servicios públicos básicos para garantizar una mano de obra calificada y productiva, adquiere importancia dentro del presupuesto público a raíz de las necesidades del proceso de industrialización. Los gastos en educación, salud y asislencia social aumentaron de menos de un $15 \%$ del presupuesto nacional a tinales de la década de los treinta, a más del $25 \%$ en los primeros anos del cincuenta. Asimismo, las asignaciones a obras públicas aumentan más de 3 veces, por lo que su participación dentro del presupuesto estatal sube de $7 \%$ a $17 \%$ entre 1952 y 1957 (ver cuadro №. 3); en estos anos se construyen las principales carreleras del pais y la primera presa hidroeléctrica que reducirla el costo de la energía en un $25 \%$.

Refiriéndose al papel de la inversión pública en eslos anos, la CEPAL senala lo siguiente: "en la evaluación del papel que han desempenado las inversiones públicas en el desarrollo de El Salvador, hay que deslacar dos hechos importantes. El primero es que fueron el único factor de aumento de la formación de capital entre 1949 y $1953 . .$. El segundo hecho - lal vez más importante- es que gracias a dichas inversiones se amplió la capacidad productiva de los sectores básicos de la economia nacional. Se crearon de esle modo las economias externas que hicieron posible las inversiones del sector privado en la industria, en el cultivo y comercialización del algodón en equipo de transporte y en otras actividades derivadas." 12

El efecto benéfico de la inversión pública sobre la formación de capltal privado, se puede apreciar en el siguiente cuadro que presenta las tasas de crecimiento de la inversión privada y pública entre 1947 y 1957; y muestra como la lormación de capital privado reacciona positivamente, aunque con cierto "retardo," ante la expansión de la inversión pública.

El valor agregado de la manufactura aumenta $70 \%$ entre 1945 y 1950 , manteniéndose a una lasa media anual superior al $5 \%$ en la década de los cincuenta. Esta expansión de la inversión privada se concreliza en la am- 
pllación de la producción textil, derivada y a su vez potenciando la acumulación en el sector del cultivo y beneficiado del algodón; se inicia la producción industrial del calzado; se instala una fábrica de calé soluble y una fábrica de cemento, lo que posibilitó también una fuerte expansión de la construcción que aumenta de $\$ 31.8$ millones en 1948 a $\$ 113.9 \mathrm{mi}$ llones en $1956 .{ }^{13}$ Gran parte de este auge industrial descansable en un gasto público creciente, condición que se volvería indispensable para el sostenimiento de la acumulación industrial en las siguientes décadas.

Cuadro No. 3

Asignaclones presupuestarlas por ramas del gasto público 1952-1959. En miles de colones y porcentajes

\begin{tabular}{|c|c|c|c|c|c|c|}
\hline \multirow{5}{*}{ 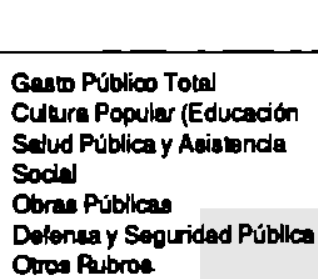 } & \multicolumn{2}{|c|}{1981} & \multicolumn{2}{|c|}{1866} & \multicolumn{2}{|c|}{1968} \\
\hline & $\begin{array}{r}112,074 \\
18,852\end{array}$ & $\begin{array}{r}100.0 \\
15.1\end{array}$ & $\begin{array}{r}178,117 \\
27.855\end{array}$ & $\begin{array}{r}100.0 \\
15.7\end{array}$ & $\begin{array}{r}173,510 \\
29,671\end{array}$ & $\begin{array}{r}100.0 \\
17.1\end{array}$ \\
\hline & 11,518 & 103 & 17,879 & 10.0 & 18.060 & 10.4 \\
\hline & 8,090 & 72 & 30,513 & 17.1 & 22.132 & 12.8 \\
\hline & $\begin{array}{l}16,530 \\
58,820\end{array}$ & $\begin{array}{l}14 . \theta \\
52.6\end{array}$ & $\begin{array}{l}24,878 \\
70,892\end{array}$ & $\begin{array}{l}14.0 \\
43.2\end{array}$ & $\begin{array}{r}7,698 \\
95.949\end{array}$ & $\begin{array}{l}12.9 \\
55.3\end{array}$ \\
\hline
\end{tabular}

FUENTE: Elaborado en base al anexo No. $3 A$ del Trabajo de Graduación de Cema, M. y Martinez, M. "Evolución y análisis critico de la tributación en El Salvador. Bases para una reforma tributaria."

UCA, Marzo 1987, Pág. 195

Por otro lado, la estnuctura tributaria consolidaba su carácter fuertemente dependiente del comercio exlerior y decididamente orienlada a favorecer la acumulación industrial. Además del fuerte impulso del gasio púbico, las dificultades para ampliar el mercado y garantizar niveles adecuados de "competitividad" y rentabilidad aduanera, que se convierte en mecanismos básicos para la expansión industrial desde la década del cincuenta originando un creciente sacrificio fiscal e imprimiendo mayor rigldez a la estructura tributaria; efectivamente, la politica tributaria se redeflne en estos anos, deslacándose tres medidas fundamentales: la Ley de Fomento Industrial de 1952, las reformas al impuesto sobre la exportación de café y el uso de los derechos arancelarios como medida proteccionista a partir de la segunda mitad de la década del cincuenta.

Mediante la Ley de Fomenlo Industrial se otorga dispensas de impuestos sobre la importación de insumos, bienes de capilal y otros materiales requerimientos para la acumulación industrial; pudiendo llegarse hasla la dispensa de los impuesios sobre el capital, sobre la renta y la producción. Para asegurar una "reserva de mercado" interno y "caplurar" 
Cuadro No. 4

Tasas de crecimlento de la Inversión públlca y prlvada (1947-1957)

\begin{tabular}{|l|c|c|c|}
\hline & $1947-1950$ & $1950-1953$ & $1953-1957$ \\
\hline Inversión Privada & 4.0 & -1.8 & 23.8 \\
Inversión Pública & 44.4 & 29.6 & -2.7 \\
\hline
\end{tabular}

FUENTE: Dada Héctor H. "La economia de El Salvador, y la integración Centroamericana (1945-1960)." UCA Editores, San Salvador.P. 48

los mercados exlernos que aparecian con la ampliación del comercio intrarregional, la prolección aduanera se conviente en instrumento clave, ampliándose y consolidándose con la extensión del proceso integracionisla.

El sacrificio fiscal y la rigidez tributaria derivada de estas medidas, aunado a la creciente necesidad de recursos por parte del Estado y a la política de compromiso entre las principales fracciones del capilal, conduce a la implementación de reformas significativas al gravamen sobre la exporlación del café, que se convertiria en uno de lo soportes más importantes para el financiamiento del creciente gasto público en estos ańos; efeclivamente, aprovechando el alza de los precios internacionales del café, en la post-guerra, se sustituye el impuesto especítico por un gravamen advalorem y progresivo sobre las exportaciones del grano, cuya lasa máxima se mantendria desde entonces en un $30 \%$ cuando el precio del caté superara los $\$ 45 / q q$. Como resultado de esla retorma y del auge del mercado mundial, la participación de los impuesto sobre la exportación de café se duplica, pasando de $17 \%$ en 1948 a $34 \%$ de los ingresos tributarios totales en 1952 (Ver cuadro No. 5).

Mediante la modifcación del gravamen sobre las exportaciones de caté, la tracción oligárquica acepta de hecho linanciar una parte importante de la promoción industrial, como una fuente de acumulación que se volvía necesaria $\theta$ impostergable ante las debilidades y límites de la agroexportación, y que precisamente ofrecia oportunidades alternativas para la valorización del mismo capilal oligárquico. Ciertamente, el capilal oligárquico aprovechó las nuevas oportunidades ofrecidas por la industralización y acepló financiar parte de su promoción que iria en su propio beneticio; pero desde un principio delinió claramente los limites de la expansión industrial: ésta sería viable sólo en la medida que no obstaculizarála dinámica de la fuente fundamental de generación de excedenles, que era y continuaría siendo, la agroexportación. 
CUADRO NP 5

Estructura Trlbutarla 1945-1959

En miles de colones y porcentajes)

\begin{tabular}{|c|c|c|c|c|c|c|c|c|c|c|}
\hline & \multicolumn{2}{|c|}{1945} & \multicolumn{2}{|l|}{1940} & \multicolumn{2}{|l|}{1952} & \multicolumn{2}{|l|}{1956} & \multicolumn{2}{|l|}{1959} \\
\hline Ingresos Tributarios & 26,414 & 100.0 & 46,104 & 100.0 & 106,381 & 100.0 & 157,776 & 100.0 & 141,067 & 100.0 \\
\hline 1. Impuestos Directos & 4,418 & 16.7 & 4,223 & 9.2 & 13,399 & 9.2 & 20,776 & 10.8 & 23,223 & 15.5 \\
\hline $\begin{array}{l}\text { 2. Impuestos Indirectos } \\
\text { 2.1. Impuestos sobre }\end{array}$ & 21,996 & 63.3 & 41,882 & 90.8 & 92,982 & 90.8 & 137,000 & 89.2 & 117,844 & 84.5 \\
\hline Comercio Exterior & 13,018 & 49.3 & 30,292 & 65.7 & 68,155 & 68.2 & 102,533 & 68.4 & 83,166 & 61.8 \\
\hline a) Sobre Imporlaciones & 11,242 & 42.6 & 22,292 & 48.3 & 34,740 & 33.2 & 59,030 & 36.3 & 58,365 & 38.7 \\
\hline $\begin{array}{l}\text { b) Sobre Exportaciones } \\
\text { 2.2. Impuestos Indirectos Int. }\end{array}$ & 1,775 & 6.7 & 8,000 & 17.3 & 32,463 & 34.1 & 43,503 & 32.1 & 24,801 & 23.1 \\
\hline $\begin{array}{l}\text { a) Sobre Consumo de Prod. } \\
\text { b) Sobre Actos Jurldicos y }\end{array}$ & 7,053 & 26.7 & 9,171 & 19.9 & & - & 29,287 & 17.8 & 29,060 & 19.1 \\
\hline Transacciones & 1,540 & 5.8 & 1,767 & 3.8 & 15,847 & 14.5 & 4,504 & 2.7 & 4,994 & 3.2 \\
\hline c) Otros Impuestos & 384 & 1.4 & 652 & 1.4 & 8,980 & 8.1 & 675 & 0.4 & 624 & 0.4 \\
\hline
\end{tabular}

Fuente: Cema, M. y Martinez, M. Op. Cit., Anexo Ne 2.

ث 
La contracción del mercado mundial a finales del cincuenta evidencio nuevamente el carácter dependiendo de la acumulación capltalista y de las linanzas públicas en nuestro pais. La tasa de crecimiento del PTB a precios corrientes disminuye de un promedio de $6.3 \%$ en la primera mitad de la década, a 2.6\% entre 1958-1962; la inversión privada se contrae de $12.8 \%$ a $2.5 \%$ en esos mismos ahos; la inversión pública también se contrae drásticamente. Asímismo, el nuevo gravamen sobre las exportaciones de calé alianzaba el carácter dependiente de los ingresos tributarios; efectivamente, las recaudaciones sobre la exporlación hablan alcanzado en importancia al gravamen sobre las importaciones, y si en 1945 ambos impuestos conlribuian con la mitad de los ingresos tributarios totales, en 1956 su participación habla aumentado a casi el $70 \%$, lo que en términos absolutos significa un incremento de $₫ 13$ millones a más de $屯$ 100 millones en las recaudaciones de impuestos sobre el comerclo exterior (cuadro No. 5). La calda de los precios internacionales del café se traduce en una disminución de más del $50 \%$ en las recaudaciones de este impuesto entre 1957 y 1960, por lo que su participación dentro de la estructura tributaria vuelve a los niveles experimentados en 1948 (17\%). Esla contracción en las recaudaciones del gravamen sobre las exportaciones de calé se mantuvo durante loda la década del sesenta, recuperándose lentamente en los primeros años del setenta pero manteniéndose muy alejado de los niveles alcanzados durante el auge de la postguerra; no es sino hasla 1976-1977 que el gravamen sobre las exportaciones de café recupera $\theta$ incluso supera los niveles de post-guerra, participando con un $40 \%$ de los ingresos tributarios totales en este úllimo ano. Nuevamente, este auge se esfumaría rápidamente al arribar a la actual década.

El carácter tendencial a la baja de los precios intemacionales del café y la rigidez tributaria derivada de una política benefactora y protectora de la acumulación industrial, van a definir por su lado olro factor clave que desembocarla en la crisis fiscal que se manifiesta claramente en la década del selenta. El sacrificio fiscal derivado de una polftica tributaria promotora de la industralización se convertiría en el principal lasire que desde entonces arrastraría las finanzas públicas, cuyo peso se acrecentaría significativamenle a partir de la década del sesenta con la extensión del proceso integracionista y se vuelve aún más elocuente en los años setenta, cuando ante el fracaso del mercado común se intenta relanzar la acumulación industrial mediante el estímulo a la inversión extranjera, estrategia en que las ventajas fiscales consliluyeron una "carnada" muy apetecida por el capital transnacional. Efectivamente el comportamiento del gravamen sobre las importaciones en las últimas décadas nos ofrece una muestra clara del elevado y creciente costo que ha significado para las finanzas públicas la ampliación de los incentivos liscales para el to- 
mento induslrial; asi la participación de los impuestos sobre las importaciones se contrae de $45 \%$ de los ingresos tributarios totales en 1961 , a $24 \%$ en 1968; aún más, en la década del setenta, con la estrategia de atracción de la inversión extranjera la participación de los derechos arancelarios disminuye de $24.5 \%$ en 1971 , a sólo $15 \%$ de las recaudaciones Iributarias de 1976.

\subsection{DInámica industrlal y crlsls flscal (1960-1978)}

Para finales de la década del cincuenta, el proceso de industralización muestra claramente sus rigiceces esiructurales, que se ampliarian y profundizarían en las siguientes décadas y que se manifestaban de múltiples formas, destacándose: el reducido mercado interno; la poca capacidad de absorción de mano de obra por la acelerada mecanización del proceso productivo; la incapacidad de un desarrollo industrial aulosostenido, derivado lanto de la estrechez del mercado como de la incapacidad de desarrollar un aparalo productivo integrado.

Para 1958, sólo las actividades de "alimentos, bebidas y tabaco" y la de "textiles, vestuario e industria del cuero," generaban el $82 \%$ del valor agregado del seclor industrial14 Además, el carácter concentrador y marginador de la acumulación labril se manilestaba claramente desde mediados del cincuenta; así, en 1956, la gran empresa manulacturera (con más de 100 personas ocupadas) representaba sólo el 1\% del total de establecimientos, pero participaba con más del $55 \%$ de la producción brula total y del valor agregado del sector ${ }^{15}$. Para eslos anos, la mayor parte del capital invertido en la producción fabril era lundamentalmente de procedencia oligárquica; efectivamente, la expansión industrial del cincuenla se nutrió de los crecientes excedentes generados por la agro-exporlación en las posl-guerra, y fué precisamente la contracción del mercado mundial la que coadyuvó a tensionar los estrechos limites que enfrentaba la acumulación industrial oligárquica y que condujo a una fuerte recesión industrial a finales del cincuenta.

Si anles del sesenta la oposición del capital oligárquico y la estrechez del mercado interno obslaculizaban la inversión extranjera en la producción tabril, las necesidades financieras y lecnológicas y la ampliación de la integración económica regional, abrieron el camino para la penetración del capital transnacional. La contracción de los excedentes provenienles de la agro-exportación que habian alimentado la inversión en la industria desde 1945 y las dificullades tecnológicas que imposibilitaban el aprovechamiento de los mercados adicionales que aparecian con la ampliación del comercio regional, serian entrentados mediante la apertura al capital extranjero, que desde finales del cincuenta y principalmente a partir de la década del sesenta, multiplica y redefine sus inversiones, abandonando los sectores tradicionales como iransporte y comunicaciones, para con- 
centrarse en la producción fabril. Electivamente, la inversión extranjera directa registrada en nuestro pais se multiplica por cinco entre 1962 y 1969; en la primera mitad de la década de los sesenta, el $54 \%$ de ese capital extranjero se localizaba en la industria manufaclurera, y para la segunda mitad de la década ese porcentaje alcanzaba el $70 \%$, mientras los rubros tradicionales de transporte y comunicaciones absorbian menos del $1 \%$ del capital transnacional. ${ }^{16}$

Más del $80 \%$ de la inversión extranjera en la producción fabril se concentró en sólo 3 ramas industriales: la rama 32 (textiles, prendas de vestir e industria del cuero), la rama 35 (fabricación de sustancias químicas e industriales) y la rama 38 (fabricación de productos melálicos, maquinaria y equipo). El comportamiento del capital extranjero en estas 3 ramas refleja las capacidades y rigideces de la dinámica industrial en EI Salvador.

Durante el auge del mercado común y ante los mayores requerimienlos de insumos y equipo para la expansión industrial del sesenta, el capital transnacional en "alianza" con la burguesía local, se orienta preferenlemente a impulsar las ramas 35 y 38 , aprovechando un mercado que se derivaba y ampliaba con la expansión industrial; efectivamente, en la segunda mitad de la década del sesenta, el 53\% de la inversión extranjera en la producción fabril se orientó a la fabricación de sustancias químicas e industriales, y el $20 \%$ a la producción de maquinaria y equipo. ${ }^{17} \mathrm{La}$ concentración de más del $70 \%$ del capital extranjero en estas dos ramas industriales, le posibilitó un control estralégico de la acumulación industrial en El Salvador; ciertamente, la producción de sustancias quimicas, maquínaria y equipo, adquiere carácter estratégico tanto por ocupar "lecnologia de punta" como por dedicarse a la fabricación de insumos y equipo para la producción industrial, además de constituir un eslabón básico que afianzó la incorporación y sometimiento de la acumulación industrial a las necesidades del capitalismo mundial y de su nuevo centro hegemónico, los Estados Unidos. La nueva etapa de desarrollo del capitalismo mundial, entraba en correspondencia y exigla la "modernización" de la producción fabril en la periteria, que en nuestro pais se concretiza en el fuerte impulso de la industria química y metal-mecánica básica durante la década del sesenta.

La decidida penetración del capital extranjero en la producción tabril, aceleró el proceso de concentración y cenlralización de capital. Entre 1961 y 1971, la producción de la industria química y derivados del petróleo (rama 35 código CIIU) aumentó más de cinco veces, destacándose la hegemonia de la gran empresa; efectivamente, los establecimientos con más de 100 personas ocupadas controlaban el $15.7 \%$ del valor brulo de la producción en 1961, mientras en 1971 generaban el $30 \%$ y en 1978 alcanzaban el $46 \%$. La producción de la industria melal-mecánica básica (rama 38) aumentó más de 15 veces entre 1961 y 1978, y el con- 
trol de la gran empresa subió de $19 \%$ a $65 \%$ de la producción tolal de esa rama entre esos mismos años. La rama 32 , que absorbió más de la tercera parte del capilal extranjero orientado a la producción tabril duranle las décadas del sesenta, y setenta, experimentó el ritmo más acelerado de concentración y centralización del capital en la industria manulacIurera; el $0.5 \%$ de establecimiento industriales de esta rama clasilicados como gran empresa, generaban el $37 \%$ de la producción bruta en 1951 , mientras en 1961 controlaban el $69 \%$ y para 1978 superaban el $85 \%$ de la producción total de la rama. ${ }^{18}$

El relanzamiento de la acumulación industrial a partir de la ampliación de la integración económica regional y del fuerte impulso derivado de las transnacionalización del capital, acelera el proceso de concentración y centralización de capital en todo el sector industrial; así, en 1961, el $0.5 \%$ de los establecimientos industriales generaban el $52.7 \%$ de la producción bruta total, mientras en 1978, el $2 \%$ de los establecimientos clasificados como gran empresa controlaban el $72 \%$ de la producción total. A diferencia de la expansión industrial de los años cincuenta en la que la acumulación de capital no condujo inmediatamente a la destrucción de la pequena producción fabril, sino más bien el número de eslablecimientos de la pequena empresa se habrían incremenlado de 8,033 en 1951 a más de 18,000 en 1961; en las décadas del sesenta y setenta, la concentración y centralización del capital en la aclividad labril diezmó a la pequena produción, cuyo número podria haber disminuido en un $50 \%$ entre 1961 y $19788^{19}$

Otra forma de observar la "lusión" de capilales particulares hacia una mayor concentración y centralización, lo constiluye el creciente número de lirmas induslriales que se organizan juridicamente como Sociedades Anónimas (S.A.) y como Sociedades Anónimas de Capital Variable (S.A. de C.V.), cuya participación aumentó del $5 \%$ en 1961 a más del $32 \%$ de los eslablecimientos industriales en 1978. En 1961 esos establecimientos ocupaban al $20 \%$ de la mano de obra del sector, mientras en 1978 controlaban el $75 \%$ del personal ocupado en la producción fabril; además, en este úllimo año las firmas indusıriales organizadas como S.A. y S.A de C.V., poseian más del $90 \%$ del valor de los aclivos fijos del seclor industrial y generaban el $90 \%$ de la producción bruta del sector ${ }^{20}$

Este fuerte impulso de la acumulación y centralización de capilal en la producción tabril, se sustentaría y consolidaria a expensas de la prolundización de los desequilibrios estructurales. El desempleo estructural se vió potenciado por la mecanización del proceso produclivo; la expropiación de los pequenos productores fabriles y su sometimiento a las necesidades de acumulación del gran capilal, ampliaria y profundizaria la pobreza; la creciente dependencia de insumos y maquinaria importada y la escasa elasticidad de la demanda interna y externa para la producción 
fabril, agudizaría el desquilibrio extemo conduciría a un rápido agolamiento de la acumulación industrial. Además, la expansión industrial de las décadas del sesenta y selenta, descansaría en una política fiscal promotora y benefaclora de ese tipo de acumulación; la subordinación del presupuesto público a los requerimienlos del proceso de industralización, condicionada por los límites y debilidades de esta fuente de acumulación de capital, definiría claramente los factores generadores de la crisis fiscal que se sumaría y complejizaría en la crisis general del sistema.

\section{a. Requerimlentos flscales de una Industrla subsidlada.}

Como senaláramos antes, la naturaleza subsidiada de la acumulación industrial en El Salvador se manilestaba desde la década del cincuenla. La estrechez del mercado y la "compelitividad" y rentabilidad de la producción fabril, se enIrentaría con un gasto público creciente y una política tributaria benefaclora de la acumulación industrial; estas caraclerísticas nos permitían detectar, desde finales del cincuenla, los gérmenes de la crisis fiscal, que se profundizan y dimensionan en las siguientes décadas en la medida que se amplía y agudiza el carácter monopólico y transnacional de la acumulación fabril. La subordinación y rigideces del presupuesto público se intensilica precisamente porque ahora tandrá que alender no sólo las necesidades de valorización del capital industrial de procedencia oligárquica, sino que a partir de la década del sesenta las inanzas públicas se entrentarian también a los requerimienlos de la acumulación fabril a nivel mundial; es decir, el presupuesto público se enfrenta a un capital más poderoso, altamente concentrado, centralizado y transnacionalizado.

Algunos esludios econométricos muestran cuantilativamenle el electo benéfico sobre la acumulación industrial derivado de un rilmo sostenido de crecimiento del gasto público, como el experimentado en nuestro país en las décadas del sesenta y selenta, concluyendo que la expansión del gasto ha posibilitado el mantenimiento de ritmos de acumulación industrial por encima de los niveles permitidos por la propia dinámica de funcionamiento del aparalo productivo; aunque estos efectos beneficos han sido neutralizados por el carácter trunco y dependiente de la acumulación industrial en nuestro pais y por la naturaleza regresiva e injusla de las fuentes de financiamiento público..21 De esta manera, la subordinación del presupuesto público a los requerimientos del proceso de industrialización, se habría traducido en la profundización de la crisis fiscal en la ampliación de los desequilibrios estructurales.

Sin embargo, la expansión industrial de los años sesenta y setenta no puede ser comprendida al margen de esta creciente y decidida subvención estatal. La creación de "economías exlernas" mediante el desa- 
rrollo de la infraestructura económica y social en los núcleos urbanos más importantes, principalmente San Salvador, coadyuvó fuerternente a la acumulación de capital. Entre 1962 y 1967, el 50\% de la inversión flsica del sector público se deslinó a carreteras, energla y teléfonos. Para proveer la mano de obra calificada y productiva, y a bajo costo para el capital, se ampliaron los servicios de educación y salud, cuyas asignaciones dentro del presupuesto público aumentaron de $32 \%$ en 1961 a $42.3 \%$ en 1968 (ver cudro No. 6).Se promovieron los bachilleralos "diversiticados" y las carreras técnicas de las universidades; entre 1963 y 1969, los alumnos inscritos en bachillerato industrial y en las carreras de ingenierla de las universidades, aumentaron más de 3 veces. Las translerencias a instituciones paraestatales que prestan servicios públicos básicos para el "abaratamiento" del costo de reproducción de la tuerza de trabajo, también experimentaron incrementos significativos y permanentes,

Cuadro No. 6

Asignaclones presupuestarlas por ramos del gasto públlco 1961-1968. En miles de colones y porcentajes

\begin{tabular}{|c|c|c|c|c|c|c|}
\hline \multirow[b]{2}{*}{$\begin{array}{l}\text { Gasto Público Total } \\
\text { Culura Popular (Educación) } \\
\text { Solud Pública y Asistencia }\end{array}$} & \multicolumn{2}{|c|}{1001} & \multicolumn{2}{|c|}{1866} & \multicolumn{2}{|c|}{1068} \\
\hline & $\begin{array}{r}185.291 \\
39,827\end{array}$ & $\begin{array}{r}100.0 \\
21.5\end{array}$ & $\begin{array}{r}245,618 \\
56,064\end{array}$ & $\begin{array}{r}100.0 \\
22.8\end{array}$ & $\begin{array}{r}227,184 \\
82,374\end{array}$ & $\begin{array}{r}100.0 \\
27.5\end{array}$ \\
\hline Social & 19,621 & 10.8 & 27.700 & 11.3 & 33,623 & 14.8 \\
\hline Obras Públieas & 24.922 & 13.4 & 27,691 & 11.3 & 17,454 & 7.7 \\
\hline Delensa y Segurided Públice & 23,034 & $12 . .4$ & 28,138 & 14.7 & 35,144 & 15.5 \\
\hline Oros ramos & - & - & 36,136 & - & - & - \\
\hline
\end{tabular}

FUENTE: Ministerio de Hacienda. Informes Complementarios Constitucionales. Varios años.

aumentando 6 veces el monto de sus asignaciones entre 1960 y 1969 , destacando fundamentalmente el aporte estatal para el Instituto Salvadoreño del Seguro Social. Por otro lado, el apoyo financiero del Estado a la acumulación privada cobra mayor imporlancia a partir de la década del sesenta, que en estos años se traduce en el fortalecimiento del INSAFI (creado en la década pasada con el nombre del INSAFOP) y orientado a proporcionar créditos subsidiados para la inversión industrial. Con todo ello, se define y consolida un gaslo público que se caraclerizaría por su alto ritmo de crecimienlo y una completa subordinación a las necesidades del proceso de acumulación industrial.

Por su lado, la naturaleza regresiva y dependiente de las fuentes de financiamiento público, se acentúan dramáticamente a partir de la década del sesenta; no sólo se agudizará el carácter injuslo y dependiente de la 
tributación, sino lambién se retonara decididamente al endeudamiento externo como fuente fundamental para el financiamiento de la inversión pública, lo que no se habia hecho en las dos décadas anteriores. Electivamente, sólo durante el segundo semestre de 1963, los proyectos de inversión pública terminados y negociados fundamentalmente con la AID y el BIRF, aportaron $\$ 99.4$ millones, el $55 \%$ de los cuales se destinaron a telecomunicaciones y energía, y $\$ 11.25$ millones al INSAFI; 22 este monto de recursos exlernos representaba más de la mitad del presupueslo público de 1963, que fué de $\$ 187$ millones. Para 1964 se estudiaban préstamos adicionales por más de $₫ 70$ millones, que representarla casi el $40 \%$ del gaslo público total de ese ano. Este endeudamiento externo se profundizaria y volveria irreversible en las siguientes décadas; entre 1964 y 1970, la deuda pública externa del gobiemo central aumentaría de 40 a casi 100 millones de colones, y para 1978 superarla los 500 millones de colones.

Por otro lado, partir de la década del sesenta, se acentúa y define claramente la rigidez y regresividad de la estructura tributaria; al mismo tiempo que la tribularia sobre el comercio exterior se vuelve menos confiable en la medida que se profundiza su vulnerabilidad respecto al mercado muncial del calé. Desde la década del cincuenta, la reditinición de la política tributaria sobre el comercio exterior, al centrarse sobre el gravamen a las exportaciones de caté y fomentar la expansión industrial mediante el otorgamienlo de crecientes y cuantiosas dispensas fiscales en concepto de exención de los derechos arancelarios, conduce a un profundo e irreversible debilitamiento de esta fuente fundamental de ingresos tributarios, que a mediados del cincuenta aportó un $70 \%$ del total de recaudaciones. Electivamente los gravámenes sobre el comercio exterior disminuyeron drásticamente su participación dentro de los ingresos tributarios, alcanzando sólo un $35 \%$ de las recaudaciones lotales en 1968 (cuadro No.7).

La problemálica de los gravámenes sobre el comercio exterior se vuelve doblemente adversa; por un lado, ya no se podrá recurrir a los derechos arancelarios como fuente de recaudación sino, por el contrario, la constante y drástica disminución de los impuestos sobre las importaciones se convierte en resultado "nalural" y pre-requisito básico para el tipo de industrialización que se impulsaba. Por otro lado, si bien el aumen10 del gravamen sobre las exportaciones de café adquirió importancia significativa como tuenle de ingresos tribularios durante la post-guerra, en la década del sesenta su contribución se contrajo drásticamente, aportando sólo el $11 \%$ de las recaudaciones tributarias en 1968 (ver cuadro No.7). Este hecho resulta fundamental para entender la dinámica de la tributaclón en estas décadas.

La redifinición de la política lribularia sobre el comercio exterior, deri- 
vada de las necesidades planteadas por el proceso de industrialización,conducia prácticamenle a perder esta fuente de tributación que en el pasado habia sostenido la mayor parte del presupuesto público; no sólo se reduce drásticamente la participación de estos grávamenes, sino que sus recaudaciones se vuelven mucho más fluctuanles e inseguras. Cierlamente, las cuantiosas y más o menos conslantes recaudaciones sobre el comercio exterior en las décadas pasadas, descansaban en un gravamen mucho más confiable, el impuesto sobre las importaciones, que por sustentarse en el manlenimiento del patrón de consumo de los sectores de altos ingresos, experimentaba pocas fluctuaciones, porque aunque el precio del café disminuyera dráslicamente, los hábilos de consumo de los que concenlraban el ingreso no experimentaban cambios significalivos, por lo que los gravámenes sobre las imporlaciones sólo disminuian muy levemenle. Esto no sucede con el impueslo sobre las exportaciones de café, que es mucho más sensible y depende exclusivamenle del mercado mundial, sobre el que no podemos ejercer ningún conlrol.

Precisamente, la fuerte contracción, rigidez y extremada vulnerabilidad de la tribulación sobre el comercio exterior, derivada y condicionada por las necesidades que planteaba el proceso de industralización, conduciría desde los primeros años de la década del sesenta a una continua

Cudro No. 7

Estructura trlbutarla 1961 - 1968

En miles de colones y porcentajes

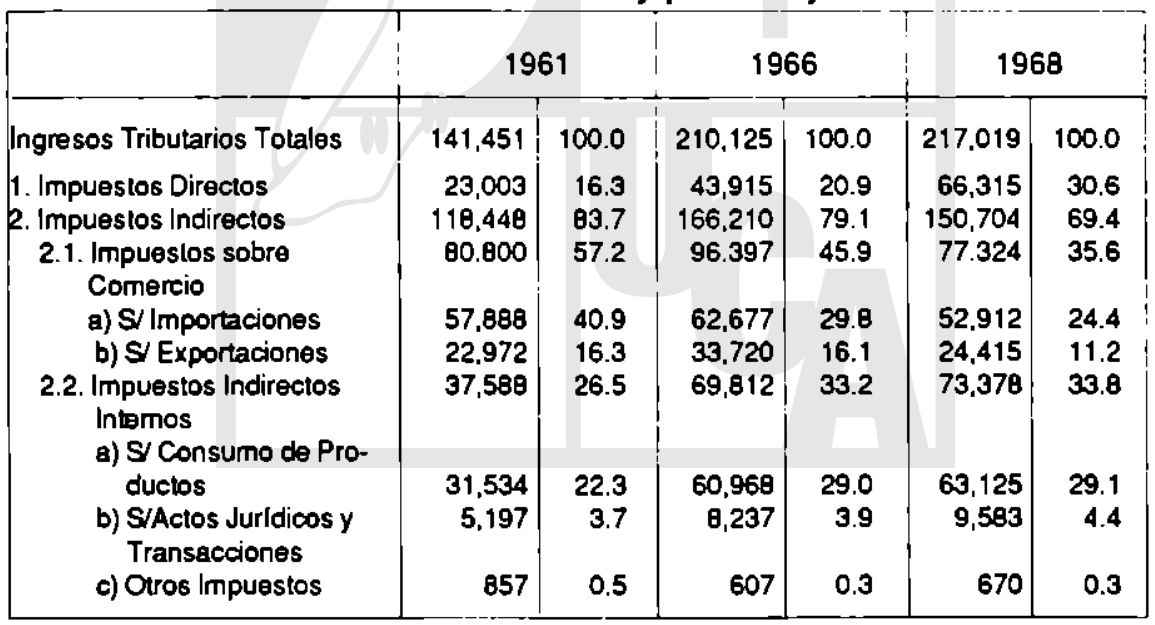

Fuente: Ministerio de Hacienda. Inlormes Complementarios Constitucionales. Tomado de Cerna, M. y Martinez, M. "Evolución y análisis cribico de la tributación en El Salvador: Bases para una relorma tributaria". Tesis de grado. Departamento de Economia, UCA San Salvador. Anexos. 
y desesperada búsqueda de fuentes tributarias alternativas que compensaran la pérdida de los gravámenes sobre el comercio exterior. En la década de los sesenla, esa búsqueda se traduce en una mayor participación de la tribulación directa, posibilitada por algunas relormas al impuesto sobre la renla, pero más que todo, resullado de las altas tasas de crecimiento económico experimenladas en dicha década; la participación de la tributación direcla aumentó de $16 \%$ a $30 \%$ de las recaudaciones totales entre 1961 y 1968 (cuadro No. 7), pero a partir de entonces los gravámenes directos marcarian una clara tendencia a disminuir su participación dentro de la estruclura tribularia.

El tipo de gravamen que se iria perfilando como la mejor allernativa para compensar la pérdida de recaudaciones sobre el comercio exterior, es aquel que recae sobre el consumo inlerno y las ventas, que por su amplitud y regresividad prolundizará el carácler injuslo de la estructura tributaria. La parlicipación de eslos gravámenes aumenta decididamente desde la década del sesenta; mientras hasta finales de la década del cincuenta los impuestos sobre el consumo interno y las ventas mantuvieron una partipación promedio de un $20 \%$ de las recaudaciones tributarias tolales, en 1961 aportaban ya el $26 \%$, alcanzado casi el $34 \%$ de los ingresos de 1968 (cuadro No.7).

En la medida que se acenluaba la vulnerabilidad y rigidez de la tributación sobre el comercio exterior y que se alcanzaban los límiles que enfrentaba la tributación directa, los impuestos sobre el consumo y las ventas acenluaban su importancia y su regresivo impacto; así desde principios de la década del sesenta se perfila y desarrolla claramente el instrumento tributario especilico que serviria como alternativa para enIrentar la fuerle contracción y poca conliabilidad de los gravámenes sobre el comercio exterior, los limbres tiscales, cuyas "virtudes" se descubrirían desde 1970, cuando al aumentarse la lasa del impuesto de 1 por mil a 1 por ciento, sus recaudaciones crecieron más de 4 veces, de $₫ 9.7$ millones en 1970 a casi 40 millones en 1974; además, los mayores rilmos de inflación que se experimentarian a partir de este último ano, revelarian la segunda gran "virtud" de impueslo de limbres: que es altamente elástico respecto al crecimiento de los precios; electivamente a pesar que la tasa del impuesto se mantuvo en $1 \%$ durante loda la década del setenta, como resultado de las mayores lasas de inflación experimentadas, entre 1974 y 1978 las recaudaciones del impuesto de timbres se duplicaron en esos años. En la década de los ochenta, la prolundización de la crisis estructural y los requerimientos económicos y politicos de la guerra, acentúan dramáticamente la regresividad del presupuesto público y de sus fuentes de financiamiento, consolidándose el impuesto de timbres como la principal tuente Iribularia, aumentando su participación de $7.6 \%$ en 1979 a $26 \%$ de las recaudaciones oblenidas en 
1985, llegando a superar los ingresos provenientes del gravamen sobre las exportaciones de calé, asi como las recaudaciones generadas por el conjunto de impuestos directos.

La continuada contracción, rigidez y vulnerabilidad de los impuestos sobre el comercio exlerior, el rápido agotamiento y los estrechos limites de la tributación directa, la profundización del carácler regresivo e injusto de la estructura tributaria y la dinámica fuertemente expansiva del gasto público, todo ello condicionado y como pre-requisito básico del tipo de industralización que se impulsaba, resultaba muy evidente y peligroso impacto y dinámica expansiva eran incluso reconocidos oficialmente desde finales de la década del sesenla. Durante la Segunda Reunión Conjunla al consejo Económico y Monetario Centroamericano en 1968, Ralael Glower Valdivieso, en ese entonces Ministerio de Economla de El Salvador, sehalaba que: "Cometerlamos un gravisimo error si creyesemos que los problemas de la balanza de pagos y crisis fiscal son fenómenos pasajeros, creados por al interterencia de factores dirigistas..es evidente que el desarrollo del estrato industrial centroamericano y el perfeccionamiento del Mercado Común han significado sacriticios de orden fiscal. No tendriamos, seguramente, mayores dificultades en lo referente a ingresos fiscales si hubiéremos negado al empresario Centroamericano la oportunidad de importar materias primas libres de aforos y si no hubiésemos eslablecido liberalidades en lo que se retiere a exenciones del impuesto sobre al renta. 23

Electivamente, los factores generadores de la crisis fiscal se manlfestaban claramente, y ya desde la década del sesenta hablan entrado en una dinámica expansiva e irreversible, que con la saturación y crisis del mercado regional y los requerimientos fiscales para un nuevo relanzamiento de la acumulación industrial, desembocarlan abiertamente en una crisis fiscal prołunda en la década del sesenta.

\section{b. La Crisls Flscal. Naturaleza y DInámica de la Crisls}

El agotamiento del mercado común y de la dinámica expansiva de la producción labril a finales del sesenta, exigió aún mayores sacriticios $\theta c 0-$ nómicos y sociales para posibilitar la continuación del proceso de acumulación de capital. El nuevo relanzamiento de la producctón indusirial se sustentarla en la ampliación de las facilidades y apertura al capital extranjero, asl como en la profundización de una politica fiscal promotora y benefactora de la acumulación fabril; todo ello conduclría a un mayor tensionamiento de las rigideces y desequilibrios económicos y sociales, y a una crisis estructural profunda a linales de la década del setenta.

Las mayores facilidades y apertura al capital extranjero se garantizo mediante una serie de mecanismo y reacomodos instilucionales, cuya manifestación más elocuente lo conslituyó la "Ley de Fomento de 
Exportaclones," que se creo en 1970 y quedó definitivamente adecuada a los requerimientos del capital transnacional con las modificaciones implementadas en 1974; con esta ley se persegula "olorgar incentivos a las empresas establecidas en el territorio nacional que exporten sus productos tuera del mercado Centroamericano." Hay que tener en cuenta que, como los hemos sefialado anteriormente, las enormes "liberalidades" para la concesión de incentivos fiscales de fomento industrial ha constituido un prerequisito básico para el tipo de industrialización impulsado en nuestro pals desde la década del cincuenla ${ }^{20}$, benelicios de los cuales ya estaba gozando la inversión extranjera; sin embargo la "Ley de Fomento de Exportaciones" que entra en vigencia en la década del setenta está dirigida lundamentalmente al capilal tansnacional, consolidando los mecanismos de sometimiento de los instrumentos fiscales a los requerimientos del proceso de acumulación capitalista mundial.

De acuerdo con esta ley de fomento de exportaciones se crea el régimen de zonas trancas y la correspondienle infraestruclura a cargo del Estado; se crean facilidades para la libre e irrestricta remisión de utilidades y dividendos del capital extranjero; se crea el Institulo Salvadoreno de Comercio Exterior (que luego se convertirá en Ministerio), el Fondo de Garantía para créditos de pre-exportación y Exportación (con fondos del Estado), el seguro de créditos de exportaciones y el Cerlificado de Compensación tributaria adernás de conceder exenciones totales (100\%) de los derechos arancelarios para importación de maleria prima y equipo, asi como exención total del pago de impuestos directos, (impuestos sobre la rema, sobre las utilidades de las empresas y de los socios individuales, y del impuesto sobre el pairimonio). La ampliación de los est(mulos orientados directamente al capital transnacional, condujo a un aceleramiento de la Inversión extranjera en nuestro pals, cuyos montos se triplicaron entre 1970 y 1979.

SI blen la producción de las ramas estratégicas de la industria (ramas 35 y 38) continuó mostrando una fuerte dinámica expansiva en la década del setenta, el tensionamiento de las rigideces estructurales sobre las que se sustentaba se profundizó duranle la década, quedando muy claros los estrechos limiles que entrentaban los intentos de lograr cierto grado de integración del aparato productivo, que en la década del sesenta se habla manifestado en cierta diversificación de la producción al habllitarse e impulsarse la industria quimica y de equipo básico. Precisamente, el luerte componente Importado de la producción de estas ramas 25 prolundizaba y habla vuello irreversible la tendencia al desequlibrio externo, mostrando su incapacidad para generar demanda interna adicional y neutralizando los efectos benéficos de la política fiscal expansiva. La tendencia al eslancamiento de la inversión industrial y al agudizamiento de los desequilibrios estructurales era ya evidente desde 
la década del sesenta y el rompimiento del mercado común, aunado a los mayores requerimientos para la expansión industrial del selenta, profundiza y define claramente la dimensión y gravedad de la crisis.

Precisamente, el énfasis y la dedicación exclusiva de la ley de Fomento de Exportaciones hacia el otorgamiento de benelicios fiscales a las empresas "que exporten sus productos fuera del mercado centroamericano," constiluye un claro reconocimiento oficial de los estrechos límiles e incapacidad del aparato productivo para generar demanda intema (y regional) adicional, por lo que la expansión industrial debería buscar y sustentarse en la "captura" de mercados fuera del área Centroamericana. Dado que la producción fabril salvadorena no podia competir en el mercado mundial com materias primas y equipo, la expansion industrial debia suslentarse en la reactivación de las ramas tradicionales de productos alimenticios, bebidas y tabaco (rama 31 código CIIU) y la producción de texliles y prendas de vestir (rama 32). Si bien estas han sido las ramas tradicionalmente más importantes por su participación en la producción lotal de la indusiria en nuestro pais, resulta noloria su reactivación en la década del setenta; así la rama 31 luvo una participación promedio de $₫ 750$ millones en al producción tolal del sector en la década del sesenta, pero en el setenta alcanzó una producción de la rama 32 aumentó casi 3 veces entre esas décadas. ${ }^{26}$

Anle esas circunstancias el capital extranjero readecuó su inversión dentro del sector industrial, orientando una menor cuota de nuevas inversiones a las ramas estratégicas (35 y 38), que en la década del sesenta absorbieron más del $70 \%$ de la inversión extranjera direcla registrada en nuestro pais, para dedicarse prioritamente a la producción de textiles, vestuario $\theta$ industria del cuero (rama 32). Si bien durante la segunda milad de la década del sesenta, la rama 32 sólo absorbió un $10 \%$ de la inversión exlranjera en la producción fabril, desde los primeros años de la década del setenta y de manera creciente, mantuvo una parlicipación superior al $50 \%$ del total del capital extranjero invertido en el sector industrial; por el contrario, la rama 35 (productos quimicos) que habla absorbido el $53 \%$ de la inversión extranjera, redujo su participación a sólo $11 \%$ del capital extranjero total en la segunda mitad de la década del selenta. ${ }^{27}$ Todo eslo aceleró el proceso de concentración y centralización del capital; efectivamente, hacia 1978, la gran empresa de la rama 32 controlaba más del $85 \%$ de la producción tolal de la rama, habiéndose convertido en otra alternaliva alractiva y prioritaria para el capital extranjero, que ahora controlaría no sólo las ramas estratégicas de la producción fabril, sino que acrecentaría su poder sobre la industria tradicional (ramas ejes) ${ }^{28}$, ampliando y aprovechando todas las alternativas rentables para invertir su capital y profundizando el sometimiento de la dinamica industrial a los requerimientos del capital mundial. 
La subordinación de las tinanzas públicas a los requerimientos para la valorización del capital local y mundial, se profundiza y se vuelve irreversible en la década del selenta, tensionando las rigideces y la regresividad del presupuesto público, y acelerando la dinámica de una crisis fiscal de carácter estructural. Cierlamente, la crisis fiscal de la década del setenta es el resultado del carácter concentrador (oligárquico y transnacional), marginador, trunco y dependiente de la acumulación de capital en El Salvador; precisamente la crisis fiscal constiluye una manilestación clara del agotamiento del modelo, es su resultado "natural."

Los factores generadores de la crisis fiscal entran en una dinámica fuertemente expansiva e irrefrenable desde los primeros anos de la década del setenta. El ritmo de crecimiento del gasto público se triplicó en los anos selenta con respecto a la década pasada, alcanzando una tasa promedio de crecimiento de $18 \%$ anual. Los gastos de capital absorbieron más del $50 \%$ del presupuesto público total en estos anos, mienIras en la década pasada absorbian sólo el 10\% del gasto tolal; 'sólo el gasto en inversión real aumentó más de cinco veces entre 1972 y 1978 y casi el $80 \%$ tue absorbido únicamente por tres nubros: transporte y almacenaje, energía, comunicaciones y correos; la inversión financiera, principalmente en concepto de compra de valores y préstamos al seclor privado, adquiere lambién fundamental importancia dentro del presupueslo público en la década del setenta, incrementándose de un monto de $₫ 80$ millones en 1972 a más de $₫ 400$ millones en 1978 (ver cuadro No. 8). Así, la valorización del capital descansaria no sólo en la generación de demanda adicional y las economias externas derivadas de la expansión del gasto público, sino que a partir de la década del setenta, el apoyo (subsidio) tinanciero del Eslado se convierte en un mecanismo más directo y fundamental para paliar las necesidades de valorización del capilal.

Por otro lado, es importante destacar las readecuación del gasto público en la década del setenta a nivel de sus dos grandes componentes: los gaslos corrientes y los gaslos de capital. Ciertamente, desde mediados de la década del cincuenta, la inversión pública no habia adquirido relevancia hasta los primeros años del setenta; como senaláramos antes, en la década del sesenta los gastos de capilal no lograron superar el $10 \%$ del presupuesto público, pero en la década del selenta manlienen una participación promedio superior al $50 \%$ del gasio total, constiluyendo un fuerte estímulo para la formación de capital y las ganancias privadas. Sin embargo, ya para finales del selenla la esinuctura presupuestaria va recuperando su tendencia "natural," en la que los gastos corrientes y principalmenle los de consumo recuperan su prevalencia como principal asignación presupuestaria, irenando aún más la capaciđad de gasio público para ampliar el stock de capital de la economia. Este 
Cudro No. 8

\section{Estructura de los gastos y compromleos del presupuesto públlco 1972 - 1978 \\ En miles de colones y porcentajes}

\begin{tabular}{|l|r|r|r|r|r|r|}
\hline & \multicolumn{2}{|c|}{1972} & \multicolumn{2}{c|}{1976} & \multicolumn{2}{c|}{1978} \\
\hline Gasto Total & 608.1 & 100.0 & $2,112.3$ & 100.0 & $2,446.2$ & 100.0 \\
1. Gastos Corrientes & 365.8 & 60.2 & 865.7 & 41.0 & $1,145.0$ & 46.8 \\
1.1. Gasslos de Consumo & 327.9 & 53.9 & 734.5 & 34.8 & 995.9 & 40.7 \\
a) Rermuneraciones & 241.1 & 39.6 & 415.4 & 19.7 & 657.5 & 28.0 \\
b) Compra de Bienes & & & & & & \\
y Servicios & 67.1 & 11.0 & 224.3 & 10.6 & 249.6 & 10.2 \\
1.2. Translerencia & 37.9 & 6.2 & 132.2 & 6.2 & 149.1 & 6.1 \\
2. Gastos de Capital & 242.2 & 39.8 & $1,245.6$ & 59.0 & $1,301.2$ & 53.2 \\
2.1. Inversión Real & 85.6 & 14.1 & 311.3 & 14.7 & 461.5 & 18.8 \\
2.2. Inversión Financiera & 94.7 & 15.6 & 518.9 & 24.6 & 490.4 & 20.0 \\
a) Compra de Valores y & 79.6 & 13.1 & 414.1 & 19.6 & 410.3 & 16.8 \\
Préstamos al Sector & & & & & & \\
Privado & & & & & & \\
2.3. Transterencias de Capital & 0.9 & 0.1 & 138.6 & 6.6 & 67.8 & 2.8 \\
2.4. Amortización dela Deuda & & & & & & 11.5 \\
Pública & 61.0 & 10.0 & 276.88 & 13.1 & 291.5 & 11.5 \\
a)/Rescate Deuda Intema & 47.7 & 7.8 & 250.0 & 11.8 & 249.3 & 10.2 \\
b) Rescate Deuda Externa & 13.3 & 2.2 & 26.7 & 1.3 & 32.2 & 1.3 \\
\hline
\end{tabular}

Fuento: Ministerio de Hacienda. Análisis del presupuesto por sectores.

deterioro se profundiza y complejiza en la década de los ochenta, como veremos más adelante.

Asi el cáracter fuertemente expansivo del gasto público, su extremada subordinación a los requerimientos para la valorización del capilal y su creciente incapacidad para estimular la ampliación del stock del capital y la demanda intema, constituyen los rasgos caracterislicos del comportamiento del gasto público en la década del setenta, definiéndose claramente $\theta$ intensificando su poder como factor generador de una crisis fiscal estructural profunda.

Por su lado, la rigidez y regresividad de los ingresos fiscales se intensilica en la década del setenta. El sacriticio fiscal derivado del estlimulo a la inversión industrial, principalmente mediante la Ley de Fomento de Exportaciones, consolida y profundiza la tendencia a la baja de los derechos arancelarios como fuente de recaudación tributaria; la partlcipación de los impuestos a las importaciones alcanza solo un $15 \%$ de las recaudaciones tolales a finales del selenta. Además, la exención total del pago del impueslo sobre la renta y el patrimonio, contemplados en la mencionada ley, tensionó los estrechos limites que enfrenta la tri- 
butación direcla como fuente de ingresos para el Eslado; como señaláramos antes, a excepción de la década del sententa en la que la tributación direcla experimentó un crecimiento significativo aportando un $30 \%$ de las recaudaciones obtenidas en 1968 , en la década del setenta su participación se contrae a un $24 \%$ (ver cuadro No. 9) y los intentos recientes por aumenlar la contribución de los que "más tienen", evidencian claramenle los estrechos límites y la incapacidad de aumenlar la tributación direcla, cuya rigidez se deriva y agrava con la profundización de los desequilibrios estructurales y con la dinámica de funcionamiento y el agotamiemlo del modelo de acumulación de capital en EI Salvador.

La rigidez, vulnerabilidad y contracción de los impueslos sobre el comercio exterior, se profundiza en la década del setenta; su participación se reduce de más del $50 \%$ de los ingresos Iributarios en la primera mitad de los anos sesenta a un $40 \% 10$ anos después. La extraordinaria y pasajera alza de los precios intemacionales del calé en la segunda milad de la década del setenla, suavizó temporalmente la crisis fiscal que se había delinido a lo largo de la década, Iraduciéndose en un incremento de $\$ 400$ millones en las recaudaciones del gravamen sobre las exportaciones de caf́; aunque ya para 1978 estas recaudaciones nuevamente se reduclan drásticamenle, aportando sólo para 244 millones en esle ano (ver cuadro No. 9).

A medida que se prolundiza la rigidez y vulnerabilidad de los gravámenes sobre el comercio exterior, y que se manifiestan claramente los estrechos límites de la tributación direcla, se recurre crecientemente a los impuestos sobre el consumo y las ventas, y principalmente al impuesto de timbres, cuya participación dentro de los ingresos tributarios aumenta más de 2 veces. Entre 1970 y 1974 (cuadro No.9), convirtiéndose en la principal fuente tributaria en la década de los ochenta.

El fuerte ritmo de crecimiento del gasto público y la rigidez y vulnerabilidad de los ingresos tributarios, se tradujo en un déficit fiscal y un endeudamienlo público que en la década del setenta entraron en una dinámica fuertemente expansiva $e$ irreversible, reflejando y coadyuvando una crisis tiscal profunda. El déficit fiscal creció más de 7 veces, de $\$ 25$ millones en 1970 a 191 millones en 1978, mientras la amortización de la deuda pública aumentó de $₫ 61$ millones en 1972 a $\$ 277$ millones en 1976; es decir, desde la segunda mitad de la década del setenta, la crisis fiscal contaba con todos los condicionamientos estructurales que la volverlan irreversible: carácler expansivo del gasto, rigidez Iributaria, délicit fiscal y endeudamiento público crecientes. Además, desde finales de esa década la dinámica de la crisis fiscal mostraba su carácter "explosivo", que con la profundización de la crisis estructural y la guerra se manifiesta claramente a mediados de la actual década. 


\section{CUADRO № 9}

Estructura Irlbutarla 1970-1978

En milles de colones y porcentajes

\begin{tabular}{|c|c|c|c|c|c|c|c|c|}
\hline \multirow[b]{2}{*}{$\begin{array}{l}\text { Ingresos Tributarios Totales } \\
\text { 1. Impuestos Directos }\end{array}$} & \multicolumn{2}{|c|}{1970} & \multicolumn{2}{|c|}{1974} & \multicolumn{2}{|c|}{1977} & \multicolumn{2}{|c|}{1978} \\
\hline & $\begin{array}{r}264,593 \\
64,564\end{array}$ & $\begin{array}{r}100.0 \\
24.4\end{array}$ & $\begin{array}{l}453,264 \\
109,435\end{array}$ & $\begin{array}{r}100.00 \\
24.1\end{array}$ & $\begin{array}{r}1,131,487 \\
237,450\end{array}$ & $\begin{array}{r}100.0 \\
21.0\end{array}$ & $\begin{array}{l}972,079 \\
285,557\end{array}$ & $\begin{array}{r}100.0 \\
29.4\end{array}$ \\
\hline 2.Impuestos Indirectos & 200,029 & 75.6 & 343,829 & 75.9 & 894,028 & 79.0 & 686,522 & 70.6 \\
\hline \multicolumn{9}{|l|}{ 2.1.Impuestos sobre ol } \\
\hline Comercio Exterior & 113,506 & 42.9 & 186,274 & 41.1 & 623,686 & 55.1 & 401,554 & 41.3 \\
\hline a) Sobre Importaciones & 65,033 & 24.6 & 93,108 & 20.5 & 163,641 & 14.5 & 157,338 & 16.2 \\
\hline b) Sobre Exportaciones & 48,473 & 18.3 & 93,166 & 20.5 & 460,045 & 40.6 & 244,216 & 25.1 \\
\hline 2.2.Impuestos Indirectos & 86,522 & 32.7 & 157,556 & 34.8 & 270,342 & 23.9 & 284,967 & 29.3 \\
\hline \multicolumn{9}{|l|}{ Internos } \\
\hline a) Sobre Consu. Produc. & 71,694 & 27.1 & 109,217 & 24.1 & 185,539 & 16.4 & 191,030 & 19.6 \\
\hline \multicolumn{9}{|l|}{ b) Sobre Actos Juridicos } \\
\hline y Transacciones & 13,858 & 5.2 & 47,560 & 10.5 & 84,174 & 7.4 & 93,314 & 9.6 \\
\hline . Timbres Fiscaies & 9,785 & 3.7 & 39,977 & 8.8 & 72,447 & 6.4 & 80,314 & 8.3 \\
\hline c) Oros Impuestos & 970 & 0.4 & 779 & 0.2 & 639 & 0.1 & 623 & 0.1 \\
\hline
\end{tabular}

Fuente: Ministerio de Hacienda. Intormes Complementarios Constiucionales.

心 


\section{Factores propagadores de la crisis flscal (1979-1986)}

El elevado costo económico, social y político derivado de la dinámica del modelo de acumulación de capilal en El Salvador, resulta muy evidente y de grandes dimensiones desde la década del setenla; el carácter concentrador, marginador, trunco y dependiente del aparato productivo ${ }^{29}$ se volvio transparente en esos anos. Con la ampliación y profundización de la pobreza, cobró impulso la manifestación política de las mayorias desposeidas, sumándose y complejizándose en la dinámica de la crisis estructural que se intensitica desde mediados de la década pasada. La profundización y estallido de la crisis a finales del selenta, se traduce en la expansión de los desequilibrios estructurales y en el afloramiento de factores (como la guerra), que amplian y aceleran la dinámica de la crisis.

La utilización de la fuerza para "controlar" o "reprimir" las protestas populares ha sido un recurso muy usado en nuestro pais, que se ha ampliado en la medida que crece el descontento popular. Entre 1972 y 1978 , los gaslos de delensa, policía y gobernación, aumentaron de $₫ 45$ a $\$ 159$ millones ${ }^{30}$; y con el desarrollo de la guerra, los gastos de delensa conslituyen un rubro prioritario del presupuesto público.

La prolundización de las dificullades y requerimientos para la valorización del capital y la dinámica de la guerra, se convierten en factores propagadores de la crisis liscal, que no sólo aceleran su dinámica, sino que agudizan la naturaleza regresiva $\theta$ injusla del financiamiento público y le imprimen un carácter "explosivo" a la crisis.

\subsection{Los requerimientos de la guerra y de la valorización del capital}

Entre 1979 y 1985 , el monto de las asignaciones al ramo de defensa y seguridad publica se multiplicó por cuatro, aumentando su participación de un $12 \%$ a más del $30 \%$ del presupueslo nacional entre esos mismos años $^{31}$. En 1985 las asignaciones a este ramo y el servicio de la deuda pública, en gran parte derivada de las necesidades del confliclo bélico, absorbian casi la mitad del gasto público tolal; es decir, la milad del presupuesto nacional se orienta a fines tolalmente improductivos, que además de no aportar nada al bienestar de la población, alimenta un proceso irracional de muerte y destrucción.

Este fuerte deterioro de la capacidad del gaslo público para estimular incrementos adicionales en el slock de capilal de la economía, como resultado de los requerimientos de la guerra, se manifiesta claramente en la readecuación de sus asignaciones entre gastos de funcionamiento y gaslos de capital. Si durante la década del setenta, los gastos del capital mantuvieron una participación promedio superior al $50 \%$ del presupuesto público, ya desde los úllimos años de esa misma década, como lo se- 
falamos anleriormenle, la eslruclura presupuestaria recuperaba su tendencia, incrementándose la participación de los gastos de funcionamiento, que a partir de enlonces absorben la mayor parte de las asignaciones presupuestarias. Entre 1979 y 1985, la participación de los gastos de funcionamienlo aumenta de $63 \%$ a $83 \%$ del presupuesto nacional. ${ }^{32}$

Obviamente, la guerra prolundiza las diticullades que enfrenta el proceso de valorización del capital, intensilicando la crisis estructural y la inviabilidad del modelo. Precisamente, la provisión de palialivos tiscales para la valorización de capilal, consliluye la otra gran prioridad del presupuesto público en la aclual década, que no sólo propaga y acelera la crisis fiscal, sino que profundiza la naturaleza regresiva del presupuesto. En efecto, además de los gaslos de delensa, las asignaciones presupuestarias que se destacan por su fuerte expansion, son los orientados al "đesarrollo de la producción", cuyo monto aumenta de \$379 millones en 1979 a $\$ 986$ millones en 1985, cantidad que superaba, incluso, las asignaciones a defensa y seguridad pública que en este último ano fueron de $₫ 725$ millones. ${ }^{33}$

Es importante destacar que el sector "desarrollo de la "producción" incluye el lomento a la producción agropecuaria, industrial, comercio y servicios; sin embargo, y a pesar de la relorma agraria que entra en vigencia desde 1980 y que se sustenlaria en el apoyo estatal, los fondos asignados al fomento agropecuario se mantienen básicamente congelados en esta década, disminuyendo su participación dentro del presupuesto público de $8.3 \%$ en 1979 a poco menos de $6.0 \%$ en 1983 . En cambio, el monto de las asignaciones al "fomento" industrial y comercial crecieron 5 veces entre esos mismos afios, alcanzando $₫ 711$ millones en 1985; es decir, la "prolección" de la producción fabril, ligada al comercio, no sólo se mantiene sino que se profundiza en la medida que se expanden las dificultades para la valorización del capilal; incluso, el rilmo de crecimiento de las asignaciones al lomento industrial y comercial, supera el crecimiento de los gaslos de delensa en ese periodo. ${ }^{34}$

Gran parle de estas mayores dificultades que enlrenta el proceso de valorización del capital, son resultado directo o indireclo de la guerra, que acelera la crisis estuctural; precisamente, casi la lolalidad de las asignaciones presupuestarias para el desarrollo de la producción industrial y comercial se orientaron a paliar las dificullades para la valorización del capital que ocasionaba el sabolaje a la energia eléctrica. Efectivamente, las asignaciones presupuestarias para la CEL, con el objelo de garantizar la comercialización y distribución de energéticos, aumentaron de menos de $₫ 100$ millones en 1979, a más de $₫ 600$ en 1983 y a más de $₫ 750$ millones en 1985; su participación dentro del presupuesto público total 
(Gobierno Cenlral e Instituciones Autónomas), se incrementa de menos del $4 \%$ en 1979 a más del $16 \%$ en 1985.35

La subordinación de los recursos del presupuesto público a los mayores requerimientos para la valorización del capital, se refleja también en el comportamiento de la inversión financiera del gobierno, principalmente en conceplo de compra de valores al sector privado, cuyos montos aumentan casi 5 veces entre 1979 y 1985, de $₫ 184$ a $₫ 991$ millones entre esos anos ${ }^{36}$, alimentando la descapitalización de las empresas y la fuga de capitales.

Obviamente, los requerimientos de la guerra y de la valorización del capital aceleran la crisis fiscal, no sólo por la expansión y subordinación del gasto, sino lambién por la rigidez, vulnerabilidad y regresividad de las fuentes de financiamiento público. No sólo se ha vuello más injusta la estruclura tributaria, sino que el financiamiento del déficit se hace recaer también sobre las mayorias marginadas y desposeldas de nuestro país, en la medida que se recurre al "financiamiento inflacionario" mediante la emisión monelaria; sólo entre 1981 y 1884, el monto acumulado de préslamos recibidos para financiar el déficit fiscal creció casi cuatro veces, de $₫ 602$ a $₫ 2,343$ millones, de los cuales un $70 \%$ correspondla a financiamiento interno procedente del Banco Central. ${ }^{37}$ El financiamiento del déficit mediante emisión monetaria contribuye a propagar la inllación; si tomamos en cuenta la rigidez de la oferla de bienes y servicios y que el multiplicador monetario en El Salvador es 3 , ese efeclo propagador es considerable. Los texios clásicos de macroeconomia definen al financiamiento del dóficil medianle emisión monetaria, como el "impuesto más cruel".

\subsection{La naturaleza regresiva e Injusta del financlamlento público}

Además de marginar aceleradamente de los beneticios del gasto público a las mayorlas desposeldas de nuestro pais, es sobre ellas que se hace recaer en mayor medida el peso de su financiamiento, profundizándose la regresividad de la estructura Iributaria. El ejemplo más elocuente to constiluye el comportamiento del impueslo de timbres, cuyas recaudaciones aumentan 5 veces entre 1979 y 1985, de $c 87$ a ¿433 millones entre esos años; aportando más de la cuarta parte de los ingresos tributarios totales en 1985, superando al gravamen sobre las exportaciones y al conjunto de los impueslos directos (ver cuadro No. 10). Esla fuerte expansión de las recaudaciones de timbres fiscales se debió a las retormas impositivas decreladas en 1980 y 1983, gracias a las cuales la tasa del impuesto de timbres aumentó de $1 \%$ a $5 \%$ entre esos anos; además, la alta elasticidad de las recaudaciones de esle impueslo anle el aumenlo de los precios y su carácter acumulativo, agudiza la incidencia regresiva de esta fuente de financiamiento público que 


\section{CUADRO N² 10 \\ Estructura Trlbutarla 1979-1985 \\ En millones de colones y porcentajes}

\begin{tabular}{|c|c|c|c|c|c|c|}
\hline & \multicolumn{2}{|c|}{1979} & \multicolumn{2}{|c|}{1981} & \multicolumn{2}{|c|}{1985} \\
\hline Ingresos Tributarios Tolales & $1,162.3$ & 100 & 990.3 & 100.0 & $1,659.4$ & 100.0 \\
\hline 1. Impuestos Directos & 277.3 & 23.9 & 297.2 & 30.0 & 384.8 & 23.2 \\
\hline 2. Impuestos Indirectos & 885.0 & 76.1 & 693.1 & 70.0 & $1,274.6$ & 76.8 \\
\hline 2.1. Impuestos sobre el Comercio Exterior & 571.2 & 49.1 & 322.5 & 32.6 & 532.9 & 32.1 \\
\hline a) Sobre Importaciones & 178.3 & 15.3 & 86.9 & 8.8 & 170.2 & 10.3 \\
\hline b) Sobre Exportaciones & 392.9 & 33.8 & 235.6 & 23.8 & 362.7 & 21.9 \\
\hline 2.2. Impuestos Indirectos Internos & 313.8 & 27.0 & 370.7 & 37.4 & 741.7 & 44.7 \\
\hline a) Sobre Consumo de Produclos & 212.4 & 18.3 & 216.5 & 21.9 & 292.8 & 17.6 \\
\hline b) Sobre Actos Juridicos y & 100.8 & B.7 & 153.4 & 15.5 & 447.6 & 27.0 \\
\hline Transacciones o Timbres & 87.8 & 7.6 & 142.0 & 14.3 & 432.8 & 26.1 \\
\hline c) Orros Impuestos & 0.6 & 0.1 & 0.8 & 0.1 & 1.3 & 0.1 \\
\hline
\end{tabular}

Fuente: Ministorio de Hacienda. Informe Complementario Constiucional. Varios ẩos. 
se ha vuelto fundamental en los últimos anos; obviamente, el impueslo de timbres se convierte también en otro elemento propagador de la inflación en El Salvador, en la medida que se incorpora como un componente del precio del producto, que se paga y acumula en cada transacción hasta llegar al consumidor final (electo "cascada"). Este "efeclo cascada" del impuesto de timbres constituye otra gran "cualidad" del gravamen, ya que con una tasa nominal relativamente baja, on la medida que el efecto se acumula en cada transacción y dependiendo de la amplitud del proceso de comercialización de los diferentes productos, se obtienen elevadas recaudaciones impositivas; según estimaciones del Ministerio de Hacienda, el impuesto de limbres vigente en El Salvador con una lasa nominal del $5 \%$, genera recaudaciones equivalentes a una tasa efectiva superior al $18 \%$.

La consolidación de los gravámenes sobre el consumo interno y las ventas, que conjuntamente aportaron el $45 \%$ de las recaudaciones totales en 1985, como la principal fuente de financiamiento público, es resullado de la luerte rigidez y contracción de la tributación directa y sobre el comercio exterior que se profundiza en estos afios. La participación de los gravámenes sobre el comercio exlerior se reduce de $49 \%$ en 1979 a sólo $32 \%$ en 1985; los derechos arancelarios continúan su frenética calda, resultando de la profundización de la crisis y de algunas medidas de política económica que prohibieron la importación de algunos productos suntuarios en los primeros años de la década; por su lado, los gravámenes sobre las exportaciones recuperan su lendencia "natural" a disminuir su participación y a demostrar una vez más su poca confiabilidad como fuente de financiamiento público; la participación de los impuestos sobre las exporlaciones se contrae de $34 \%$ en 1979 a $22 \%$ en 1985 (ver cuadro No. 10).

Por su lado, la tributación direcla mantiene una participación promedio de un poco más del 23\% entre 1979 y 1985 . Durante estos anos se maniliesta claramente la rigidez de los gravámenes direclos; y aunque formalmente estos impuestos se caracterizan por su progresividad, en la realidad adolecen de la misma naturaleza regresiva e injusta que caracteriza a la estructura tributaria en su conjunto y que se profundiza en los últimos anos. Del conjunto de gravámenes directos (sobre la renla, sobre el patrimonio vialidad serie "A"- y sobre las lansferencias de propiedades), los más importantes son los que recaen sobre la renta personal y de las empresas, que participan con más del $75 \%$ de las recaudaciones generadas por los gravámenes directos. Sin embargo y a pesar de que tradicionalmente los impuestos sobre al renta han sido considerados como los instrumentos más adecuados para lograr alguna equidad o justicia tributaria, al analizar su estruclura se aprecia la incapacidad de este instnumento tributario para lograr su objelivo en EI Salvador. 


\section{CUADRO NP 11}

Estructura de las recaudaclones del Impuesto Sobre la Renta 1979 y 1984

(Miles de colones y porcentajes)

\begin{tabular}{|c|c|c|c|c|c|c|c|c|c|c|c|c|c|c|}
\hline \multirow{3}{*}{ Año } & \multirow{2}{*}{\multicolumn{2}{|c|}{$\begin{array}{c}\text { Tramos de } \\
\text { Rente Imponible }\end{array}$}} & \multicolumn{6}{|c|}{ PERSONAS NATURALES } & \multicolumn{6}{|c|}{ PERSONAS JURIDICAS } \\
\hline & & & \multicolumn{2}{|c|}{ Contribuyentes } & \multicolumn{2}{|c|}{ Rentra Imponible } & \multicolumn{2}{|c|}{ Impuesto Pagado } & \multicolumn{2}{|c|}{ Contribuyentes } & \multicolumn{2}{|c|}{ Renta Imponitle } & \multicolumn{2}{|c|}{ Impuesto Pagado } \\
\hline & Dosde & Hastg & Número & $\%$ & Colones & $\%$ & Colones & $\%$ & Número & $\%$ & Colones & $\%$ & Colones & $\%$ \\
\hline \multirow[t]{6}{*}{1979} & 10.0 & $\mathbf{2 5 . 0}$ & 24,660 & 32.7 & 372,643 & 34.0 & 13,352 & 14.4 & 515 & 17.6 & 0,601 & 1.9 & 575.4 & 0.6 \\
\hline & 25.0 & 100.0 & 7,952 & 10.5 & 335,046 & 30.6 & 41,813 & 45.0 & 838 & 28.7 & 44,737 & 9.9 & $3,607.4$ & 4.0 \\
\hline & 100.0 & 200.0 & 522 & 0.7 & 69,125 & 6.3 & 17,605 & 19.2 & 291 & 9.9 & 41,055 & 9.1 & $5,280.5$ & 5.5 \\
\hline & 200.0 & $1,000.0$ & 165 & 0.2 & 49,522 & 4.4 & 18,853 & 20.3 & 330 & 11.3 & 138,567 & 30.7 & $26,740.8$ & 27.9 \\
\hline & $1,000.0$ & $4,000.0$ & 1 & - & 1,079 & 0.1 & 216 & 0.2 & 72 & 2.5 & 136,285 & 30.2 & $36,406.3$ & 38.0 \\
\hline & $4,000.0$ & en adalante & - & - & - & - & - & - & 14 & 0.4 & 78,339 & 17.4 & $22,904.4$ & 23.9 \\
\hline \multirow[t]{6}{*}{1984} & 10.0 & 25.0 & 45,767 & 39.3 & 653,377 & 40.6 & 19,884 & 19.3 & 623 & 18.7 & 10,331 & 1.6 & 481 & 0.3 \\
\hline & 25.0 & 100.0 & 10.094 & 8.5 & 420,134 & 26.1 & 51,450 & 49.8 & 881 & 26.5 & 45,852 & 7.2 & 3,654 & 2.5 \\
\hline & 100.0 & 200.0 & 477 & 0.4 & 63,520 & 3.9 & 16,472 & 16.0 & 305 & 9.2 & 43.171 & 6.8 & 5,554 & 3.8 \\
\hline & 200.0 & $1,000.0$ & 124 & 0.1 & 34,936 & 2.2 & 13,106 & 12.7 & 369 & 11.1 & 158,240 & 24.9 & 30,325 & 21.0 \\
\hline & $1,000.0$ & $4,000.0$ & 2 & - & 3,000 & 0.2 & 1,255 & 1.2 & 89 & 27 & 172,190 & 27.0 & 46,597 & 32.2 \\
\hline & $4,000.0$ & en adolanti & - & - & - & - & - & - & 25 & 0.8 & 202,460 & 31.8 & 58.721 & 40.6 \\
\hline
\end{tabular}

Fuente: Ministerio de Hacienda. El Salvador.

念 
En el cuadro No. 11 se aprecia claramenle que los gravámenes sobre la renta de las personas naturales se ha concentrado tradicionalmente sobre aquellos contribuyentes que podrian clasilicarse como de "ingresos medios," que se ubican en un tramo de renta imponible entre $\$ 25,000$ y $₫ 100,000$, y que en 1979 aportaron el $45 \%$ del total de recaudaciones generadas por este gravamen. Es importanle destacar que a pesar de la enorme concenlración del ingreso en nuestro pais, muchas veces evidenciada en diferenles trabajos, sólo se regislra un contribuyente con renta imponible entre 1 y 2 millones de colones en 1979 y que sólo participa con el $0.2 \%$ de las recaudaciones en ese año. Casi el $80 \%$ del tolal de recaudaciones del impuesto sobre la renla personal en 1979 se obtenian de contribuyentes con rentas inferiores a $₫ 200,000$; mientras en 1984, más del $85 \%$ de los ingresos provenian de este tramo de contribuyentes, destacando las personas con renta imponible entre $\$ 25,000$ y $\$ 100,000$, que ya para entonces aportaban el $50 \%$ de las recaudaciones totales de este impuesto (ver cuadro No. 11).

Entre 1979 y 1984, el número de conlribuyentes del impuesto sobre la renta personal aumenló de 76,000 a 119,414 personas, resullado fundamentalmente de la "captura" de contribuyentes con renla imponible inlerior a $₫ 25,000$. Efectivamenle, el número de contribuyentes con renta imponible inferior a $\$ 10,000$ aumento $50 \%$ entre 1979 y 1984 , mientras aquellos ubicados en el tramo de renta entre $₫ 10,000$ y $₫ 25,000$ se duplicó en esos mismos años; en estos tramos de renta se concentran el $90 \%$ del tolal de contribuyentes del impuesto sobre la renta personal, pero lógicamente, por su escasa capacidad contributiva, no generan ni el $20 \%$ de las recaudaciones de este impuesto, la mitad de las cuales son aportadas por las personas que declaran una renta imponible entre 25,000 y $\$ 100,000$ que en 1984 representaban el $8.5 \%$ de contribuyentes. La mayor incidencia de este gravamen sobre los tramos de "ingresos medios" y su incapacidad para alectar a los que concentran el ingreso de nuestro país, es resultado de la subordinación de los insirumentos tiscales a los requerimientos de la estructura de propiedad y de la dinámica de funcionamiento de la economia, que se manifiestan en una serie de vicios y vacios de la legislación y control tribularios, que en nuestro pais han conducido a una verdadera $\theta$ incontrolable "evasión instilu. cionalizada."

El comportamiento del gravamen sobre al renta de las personas juridicas permile evidenciar aún más los vicios y oportunidades legales que eslos gravámenes ofrecen a los que concentran el ingreso. A diferencia del impuesto sobre la renta personal, el gavamen sobre la renta empresarial se concentra en los tramos más altos de renta, de $₫ 200,000$ en adelante, que aportan el $90 \%$ del total de recaudaciones; deslacándose las empresas que declaran una renta superior a los 4 millones de colones, 
que constiluyen menos del $1 \%$ de lotal de contribuyentes pero que en 1979 aportaron el $24 \%$ de las recaudaciones y en 1984 contribuyen con más de $40 \%$ del lolal de ingresos generados por el gravamen sobre la renta empresarial (cuadro No. 11).

Si sólo tomamos en cuenta esos elementos y analizamos aisladamente el impueslo sobre la renta empresarial, podría concluirse que este gravamen cumple con el objelivo de lograr mayor equidad tributaria. Pero analizando más detenidamente este inslrumento, podemos deteclar los vicios y oportunidades que ofrece al gran capilal. En primer lugar habría que señalar la naturaleza jurídica (impersonal) que adquiere el capital y las ventajas legales que ello le confiere; en el campo tributario eslas ventajas se traducen en mayores oportunidades para evadir legal e ilegalmente el impuesto sobre al renta y en una lasa impositiva muchísimo menor que la aplicada a las personas naturales. La tasa marginal máxima que recae sobre la renta personal es de $60 \%$, mienlras que para la renta empresarial alcanza sólo un $30 \%$; además de que la renta imponible incluye sólo las ulilidades electivamente distribuidas por la empresa, quedando exentas del pago duranle 5 anos aquella parte del excedente que, al menos en teoría, se destinaria a reinversión, lo que conslituye otro importante mecanismo legal para evadir el pago del impuesto mediante la constitución de corporaciones o sociedades "fantasmas," que luego "quiebran" o desaparecen esfumándose con ellas el importe del gravamen; ese es un recurso muy utilizado por el gran capital en nuestro pais.

Resulta notorio el fuerte incremenlo de la participación de las empresas que declaran los mayores niveles de renta, principalmente las de $₫ 4$ millones en adelanle. Resulta claro deducir que las ventajas ofrecidas por el impuesto sobre la renta empresarial, aunado a la prolundización de la crisis, ha llevado a que los que concentran el ingreso busquen paliar los problemas que enfrenta la valorización del capital, transformándose en personas jurídicas y lograr de esa manera un mayor excedente disponible a expensas de las arcas fiscales; efectivamente, el cuadro No. 11 muestra cómo las personas naturales que declaran renta imponible superior a $₫ 100,000$ han disminuido su número entre 1979 y 1984, al mismo tiempo que aumenta el número de empresas que declaran rentas superiores a ese nivel.

El impuesto sobre el patrimonio (antes "vialidad serie "A") segundo en imporlancia después del impuesto sobre al renla personal y empresarial, también presenta una mayor participación de aquellos contribuyentes que concentran el capilal. En 1985, el $2 \%$ de los contribuyentes declaraban patrimonios superiores al millón de colones, pero aportaban el $57 \%$ del lotal de recaudaciones de este impuesto; aún más, las personas juridicas que declaraban su capilal superior al millón de colones, aportan un 
$90 \%$ del total de recaudaciones del impuesto sobre el patrimonio empresarial.38 Sin embargo, la reducida tasa de este impuesto lo convierte en una luente de tinanciamiento público insignificante; electivamente, en 1985 el impuesto sobre el patrimonio aportaba sólo un $3 \%$ de lotal de recaudaciones tributarias para ese año.

Los beneficios Iributarios obtenidos por el gran capilal se amplian si consideramos el enorme sacrificio fiscal derivado de la concesión de incentivos al "desarrollo industrial," que de manera continuada desde la década del cincuenta y cada vez con mayor amplitud, permiten la exención del pago de derechos arancelarios y del impuesio sobre al renta y el patrimonio a las empresas beneficiadas. Se estima que sólo en conceplo de exención de los gravámenes sobre la importación de materias primas y bienes de capilal, se generó un sacrificio liscal de 113 millones en 1979 , el $40 \%$ del cual provenia de los incentivos ofrecidos a la industria quimica (rama 35 código CIIU) y casi un $30 \%$ era generado por las empresas de las ramas 32 y $38{ }^{39}$ (producción textil y melal-mecánica básica, respectivamente); es decir, el $70 \%$ del sacrilicio liscal es generado por aquellas empresas industriales que han mostrado mayor dinamismo en el proceso de concentracion y centralización de capital, y en las que el capital extranjero se ha vuello hegemónico. El $68 \%$ del sacrificio tiscal derivado de la exención del pago de derechos arancelarios proviene de los beneficios otorgados a la gran empresa, que sólo representa un $13 \%$ de los eslablecimientos industriales; 'en relación a su valor agregado, la gran empresa ocasiona 37 veces más sacrificio fiscal que el resto del sector industrial.40

En la medida que se incrementa aceleradamenle los requerimiemlos financieros del gobierno y que se profundiza la rigidez y vulnerabilidad de los impuestos directos y sobre el comercio exterior, se intensifica el carácter regresivo e injusto del financiamiento público: se recurre cada vez más a la tribulación regresiva, al financiamiento inflacionario y/o al endeudamiento externo, que comprende aún más los escasos márgenes para un desarrollo menos dependiente y autosostenido.

\subsection{El carácter "explosivo" de la crisls fiscal}

El impacto de la profundización y dinámica de la crisis estructural en la década de los ochenta, le imprime un carácter "explosivo," incontrable. de grandes dimensiones y trascendencias, al desequilibrio presupuestario del gobierno, minimizando aún más su efecto dinamizador de la actividad económica y alcanzando los IImiles económicos y politicos de la dinámica presupuestaria. La incapacidad para controlar el fuerte ritmo expansivo del gasto, la fuerte rigidez $\theta$ imposibilidad para aumentar las recaudaciones tribularias, la profundización de los desequilibrlos estructurales, el rápido agotamiento de las políticas económicas compensalorlas y 
la prolundización de la guerra y de al crisis politica, nos conducen a la "explosion" de la crisls fiscal, a una verdadera e irreversible quiebra fiscal.

\section{a) La dinámica de la crisls}

El aceleramiento de la crisis se relleja en el ritmo fuertemente expansivo del déticit presupuesto del gobierno y en la imposibilidad de revertir esa tendencia. Ciertamente, el déficit fiscal no es algo nuevo en El Salvador, por el contrario es un resultado "normal" del funcionamiento de nuestra economia; en los últimos sesenta ahos, sólo en dos ocasiones se han registrado superávits transitorios: en la segunda mitad de la década del veinte y entre 1935 y 1957, que han sido precisamente épocas de auge del mercado mundial del café; a partir de entonces, sollo en 3 anos aislados se ha repetido semejante hazana: en 1960, 1964 y 1977. "1 Si bien es déficil fiscal es un resultado "natural," la protundización de la crisis estructural lo ha vuelto irreversible y de grandes dimensiones desde la década del setenta; mientras en 1970 ese délicit alcanzaba solo $\$ 25$ millones, en 1978 ascendía a 191 millones; y en la medida que se profundizan los requerimientos de la guerra y de la valorización de capital y se inlensifica la rigidez de los ingresos Iributarios. dicho déficit alcanza los $\$ 755$ millones en 1982.42 manteniendo esa tendencia fuertemente expansiva $\theta$ irreversible a lo largo de la década actual.

Como hemos mostrado anteriormenle, el aceleramiento del gasto público ha tratado de sostenerse recurriendo a fuentes de financiamiento fundamentalmente regresivas: los gravámenes sobre las ventas y el financiamiento inflacionario. Aún más, la insuficiencia de estas luentes de financiamiento interno ha conducido a un fuerte endeudamiento externo y a un creciente sometimiento de nuestra soberania nacional; los "donativos" del gobierno norleamericano a través de la AID para reforzar el presupuesto público, se han convertido en una indispensable y signiflcativa fuente de financiamiento, que sólo en 1984 alcanzaron un monto de 490 millones, lo que representa una tercera parte de los ingresos tributarios totales de ese ano.43 No obstamle la deuda pública acumulada superó los $€ 2,500$ millones en 1985 y el déticit fiscal continúa su frenélica marcha. Ciertamente, el "presupuesto extraordinario" financiado por el gobierno norteamericano (que según algunas estimaciones supera los $₫ 1,500$ millones anuales), ha logrado paliar la crisis financiera del gobierno salvadoreno, evitando o retardando la quiebra fiscal. Sin embargo, los IImites de estas alternativas de financiamiento, ante la gravedad y la profundización de la crisis, se vuelve transparente y su naturaleza explosiva es evidente en estos anos.

A pesar de los esfuerzos por reducir aquellos gastos "prescindibles," no relacionados directamente con la guerra y/o con la acumulación de ca- 
pital, el gasto público se distanció aún más de 10 ingresos del gobierno. No sólo resullaba preocupante el monto, sino también la composición misma del gasto; en 1985, de un gasto total de $₫ 2,360$ millones, el $83 \%$ correspondía a gastos corrientes mienlras que el $34 \%$ de los reducidos gastos de capilal se destinaban a la amorlización de la deuda pública. El $70 \%$ de los gastos totales se destinaba a 3 grandes rubros: defensa y seguridad pública ( $\$ 710$ millones), remuneraciones excluyendo delensa y seguridad pública ( 631 millones), pago de intereses y amortización de la deuda pública (\$313 millones). Esıos tres rubros absorbieron la lotalidad de los ingresos tributarios de este ano.44

La siluación fiscal de 1985 se volvía más alarmante al considerar las fuentes de financiamiento público. Los ingresos tributarios pareclan eslar sobre sus límites estructurales. los impuestos directos, que participaban escasamente con un $23 \%$ de los ingresos tributarios de ese ano, no podían incrementarse a menos que se esluviese dispuesto a "desestimular" la inversión privada y/o a sufrir las protestas desestabilizadoras del gran capital; la continua disminución de los impuestos sobre la exportación (que llega sollo $22 \%$ de los ingresos tributarios en 1985) y la poca confiabilidad de esta fuente de linanciamiento, hacia más difícil la situación del gobierno. Los impuestos sobre el consumo y transacciones internas se convierten en la principal fuente tributaria, especificamente el impuesto de timbres; pero dada su naturaleza regresiva agudizada por el electo "cascada," se ha convertido en otra causa importanle del deterioro del ingreso real de la mayoria de la población, y en la medida que el descontenlo y las demandas populares se intensitican, se restringuen aún más los escasos márgenes, económicos y polfticos, a que se enirentan los intentos por ampliar la incidencia de este gravamen.

Por otro lado, los ingresos de capital no conslituyen ninguna atternativa financiera adecuada; en 1985 este rubro sólo contribuyó con el $6.4 \%$ de los ingresos totales del gobierno. Además, el endeudamiento público alcanza niveles peligrosos; la deuda directa del gobierno central aumentó 5 veces entre 1979 y 1985, dentro de ésta, la deuda interna creció más de 10 veces. Este aceleramiento del endeudamiento interno se refleja también en la mayor participación del gobierno central en los créditos otorgados por el sistema bancario nacional, aumentando de $4.1 \%$ en 1979 a $29.5 \%$ en 1985 . Esto, además de agitar las protestas empresariales, incide en le proceso inflacionario, descargando de esta manera sobre los seclores populares ese gravamen financiero a través de mayores precios. 45

\section{b. Los "paquetazos" flscales y sus Iimites económicos y politicos}

La continuada y acelerada expansión de los desequilibrios macroeco- 
nómicos durante la década de los ochenta, ha conducido a varios intentos por "estabilizar" la crisis desde los inicios de la década. Entre las políticas más destacadas eslán: la congelación de los salarios y las plazas disponibles; los recortes presupuestarios a las ramas que prestan servicios públicos básicos; las "reformas tributarias" de 1980 y 1983 , cuyo logro fundamental fué el aumento en la tasa del impuesto de timbres; la creación de un "mercado paralelo de divisas" y los intentos por controlar la expansión fiscal y monelaria. La insuficiencia de estas resultaba evidente a mediados de la década y anunciaba la implemenlación de programas de política económica de corte ortodoxo, rigidamente cenidos a los lineamientos del FMI y la AID.

El incontenible deterioro fiscal y la profundización de los desequilibrios internos y exlernos, conducen a la adopción del "programa de estabilización y reactivación económica" en enero de 1986, cuyo objetivo en el área fiscal era reducir el déficit presupuestario y fijar el financiamiento olorgado por el Banco Central al gobierno en un máximo de 100 milones de colones. Las medidas más destacadas del programa y que ejercerlan una mayor incidencia en el área fueron, la devaluación del colón y el "impuesto de emergencia" sobre el caté, que contemplaba una tasa adicional del $15 \%$ sobre las exportaciones del grano y que junto con la extraordinaria y por lo tanto temporal alza de los precios internacionales del café, permitía esperar incrementos sustanciales en las recaudaciones sobre el comercio exterior.

Si bien la devaluación aumentaria en un $35 \%$ los gaslos corrientes y en $68 \%$ los gaslos de capital, se esperaba un incremento de más de mil millones de colones en ingresos tributarios lundamentalmente provenientes del impuesto a las exportaciones de café. A pesar de que el calé no se exportó a los $\$ 200$ previstos sino a un precio promedio de

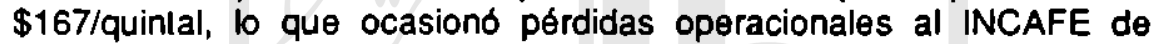
alrededor de $\$ 50 /$ quintala ${ }^{46}$, un $75 \%$ del incremento experimentado por los ingresos como resultado del "primer paquelazo," fueron aportados por las exportaciones de calé, aumentando en un $60 \%$ los ingresos Iribularios de ese ano.

Un $90 \%$ de esos ingresos adicionales, en su mayoria "'extraordinarios" o lortuilos, obtuvieron una respuesta de gasto que se vuelve permanente: los pagos de intereses y amortizaciones de la deuda pública aumenlaron en un $30 \%$; los empleados públicos lograron un aumento salarial promedio de $17 \%$; el aumento salarial y parte del incremento en los coslos de las instiluciones autónomas seria subvencionado por el Estado, por lo que hasta mayo de 1986 las transierencias presupuestadas para estas instiluciones ascendian a $\$ 500$ millones, con to que su participación en el presupuesto general aumentaba a 14\% asimismo, las transferencias al sector externo aumentan en $100 \%$ como resultado de la 
devaluación y los gastos en adquisición de activos fljos subleron un $48 \%$. Sólo un $10 \%$ de los ingresos adicionales se destinaron a gastos de capital.

Al impacto tiscal del "primer paquetazo habrla que agregarte los efectos derivados del terremolo, que podría aumentar el défecit flscal proyectado para 1986 en un $25 \%$.

La recaudación de ingresos tributarios por debajo de lo esperado, aunado a la irreversible dinámica del gasto, condujo a un déficit flscal global (excluyendo donalivos) en 1986 que oscilaría entre $\$ 600$ y 800 millones, muy superior al de 1985 que fue de $\$ 538$ millones. Las donaciones, multiplicadas por la devaluación, jugaron nuevamente un papel relevante para paliar la crisis financiera del gobierno; gracias a ellas el déficit financiero se reduciria a sólo $₫ 173$ millones en 198647

Los resultados fiscales de 1986 y las previsiones para 1987 mostraban la insuliciencia del "primer paquetazo" y la "explosion" de la crisis fiscal se vuelve transparente. El "programa de estabilización" $6 \theta$ traducla en un incremento de los gastos permanenles del Estado, mlemtras gran parte de los ingresos adicionales desaparecian con la baja en los preclos internacionales del calé. Ciertamente, el agotamiento de las fuentes tradicionales de financiamiento y las previsiones de una comtracción de más de $₫ 300$ millones en el rendimiento de impuesto a las exportaciones de calé, a pesar de mantenerse la sobretasa "temporal" a la exportación de este grano, adelantaba el anuncio del "segundo paquetazo" que de acuerdo con su fundamento "filosofico" pretenderla "avanzar un paso más en la búsqueda de justicia en nuestro pais", 48 ya que hasta ahora la tributación "cargaba más a los sectores desposeldos que pagaban el $86 \%$ del lotal que percibla el gobiemo; y los que tenlan más y ganaban más. sólo pagaban el $14 \%$

El incremento de $60 \%$ en los ingresos tributarios de $1986 \mathrm{se}$ logró a cosla de una devaluación del $100 \%$, una sobretasa del $15 \%$ en el impuesto a las exportaciones de café y una siluación extraordinaria bonanciable en los precios intemacionales de este grano; condiciones tales que no es realista suponer que pudieran presentarse de nuevo en el corto plazo. Realmente, parece ser que el primer paquelazo "exprimio" las luentes tradicionales de financiamiento público.

Ciertamente, un claro reconocimiento de la "insuficiencia" de ese programa de estabilización y del agolamiento de las fuentes tradicionales de financiamiento, to constituiria el anuncio del "segundo paquetazo." Los estrechos márgenes para la obtención de recurso a que se entrentaba el gobierno, lo llevarla a proponer una reforma Iributaria que trataría de aprovechar una fuente impositiva hasta ahora "marginada": la tributación direcla; aún a sabiendas del consecuente rechazo empresarial que, 
efectivamente , llego a convertirse en una peligrosa fuenle adicional de desestabllización; ciertamente, el descontento y las manifeslaciones empresariales de rechazo al "segundo paquetazo, llegó a convertirse en una de las mayores crisis polfticas que ha enlrentado el gobierno de Duarte.

El ataque empresarial se concentró fundamentalmente sobre 3 de los impuestos "reformados": el patrimonio, el de la renta y el impuesto de "soberanla nacional." Ciertamente, estos Ires impuestos serlan los más importantes en términos de recaudaciones Iributarias; según estimaciones oficiales optimistas, de llevarse a cabo la reforma tribularia, se generarian ingresos adicionales por unos 350 milones de colones y el $80 \%$ provendría de estos impuestos. Además, aparentemente en eslos impuestos se fundamentaba la "progresividad" de la relorma.

A lodas luces, el monto de recaudaciones esperadas no era suficiente ante la urgencia tinanciera del gobierno; estos ingresos "adicionales" apenas compensarian la baja esperada en las recaudaciones del impuesto al café. Sin embargo, resulta indispensable analizar el supuesto carácter "progresivo" de la reforma.

Cientamente, si bien las modificaciones al impuesto sobre al renta personal reducirlan el peso del gravamen hasta una renta promedio imponible de 22,500 colones, a partir de esle nivel la incidencia subirla aceleredamente, concentrándose en las rentas entre 27,500 y 60,000 colones, alcanzando su peso máximo con una renla de 35,00 colones anuales. 50

Simllar comportamiento se deriva de las reformas al impuesto sobre la remla de las empresas y el del patrimonio. Como puede obsevarse en el cuadro No. 12, con las relormas propuestas, las empresas con una renta imponible de 50,000 verlan incrementando su gravamen en más de $300 \%$; en cambio, con una renta de 500,000 colones el gravamen sólo aumenta $69 \%$ respecto a lo que le corresponderla pagar segun la ley vigente.

La mayor incidencia de la relorma tributaria sobre los sectores que poseen relativamente menores ingresos y/o capital imponible, se manitiesta también en el impuesto al patrimonio. Con las modificaciones propuestas a este impuesto, el gravamen aumetaria $300 \%$ para un capital imponible de 100,000 colones y $224 \%$ para un capital de 2 millones.

Por otro lado, el aceleramiento de la inllación en los úllimos anos vendrla a agudizar la incidencia de la relorma, ya que las nuevas lasas se colocarlan sobre al renta "inflada." Estimaciones hechas por FUSADES, muestran que el "impuesto inflacionario" (recaudaciones derivadas exclusivamente del aumento de precios), de aplicarse la reforma tributaria, akcanzarla un $100 \%$ para un capital imponible de 100,000 colones y 
llegaría a un máximo de $537 \%$ con una renta promedio de 45,000 colones."51 Es decir, la incidencia de la reforma tributaria, agudizada por al inflación, se concentraría fundamentalmente en los sectores de ingresos "medios," con rentas imponibles entre 27,500 y 60,000 colones y con un capital imponible promedio de 100,000 colones. Ciertamente, el gran capital no sería el mayomente afectado.

\section{Cuadro No. 12}

Incidencla de la relorma al impuesto sobre la renta de las empresas

\begin{tabular}{|c|c|}
\hline $\begin{array}{c}\text { Niveles de renta imponible } \\
\text { (colones) }\end{array}$ & $\begin{array}{c}\text { Aumento porcentual del gravamen como resultado } \\
\text { de la reforma, según niveles de renta imponible }\end{array}$ \\
\hline 50,000 & $329 \%$ \\
100,000 & $253 \%$ \\
500,000 & $69 \%$ \\
\hline
\end{tabular}

Fuenta: Elaborado en base a cilras procesedas por FUSADES, en "Análisis critico de la pollica fiscal," San Salvador, diciembre de 1986.

Las modificaciones propuestas al impuesto sobre la renla empresarial pretendian también eliminar uno de los privilegios tribularios de que gozan los empresarios salvadorenos, introduciendo una modificación según la cual se gravaria "a las sociedades que operan como subsidarias, por ejemplo de un "holding" y las de éste cuando la subsidiaria le Iraspasa sus dividendos." Uno de los mecanismos idóneos para evadir la tributación sobre la renta empresarial es ciertamente, la "reinversión" de los dividendos en sociedades ficticias ("Iaslamas") que luego "desaparecen" o "quiebran," esfumándose con ellas la base impositiva.

El rechazo empresarial de las reformas al impuesto sobre al renta y el patrimonio,se fundamentó en el sefialamienlo de los electos "desincentivadores" de lales modificaciones, haciendo énfasis en su carácler contradictorio respecto a la necesidad de "reactivar la economia." De acuerdo con los planteamientos empresariales, la reforma tributaria conduciria a una mayor "dolorización" y luga de capitales, a un endeudamiento nelo artificial, a la fragmentación deliberada de la propiedad, al reliro masivo de depósitos como resultado de la eliminación del "secrelo bancario" y a la intensificación en el uso de fórmulas para reducir artificialmenle el capilal imponible. Al mismo tiempo que se "debilitaria el desarrollo empresarial," en la medida que los nuevos gravámenes reslarian "compelitividad" a las empresas que producen para la exportación y a la producción nacional 
que compite con las importaciones, obstaculizando seriamente la "reactivación económica." 52

El rechazo empresarial a la "ley del impuesto para la defensa de la soberania nacional" se fundamento, en cambio, en análisis de tipo jurídico del decreto. Este impueslo se rechazaba porque era "inconstitucional" al justificarse argumentando que los fondos generados se utilizarían para la "defensa de la soberanía nacional," lo cual sólo serla válido si se tratase de una "agresión externa" que, según los voceros empresariales, no es el caso salvadoreno, sino más bien, al guerra en El Salvador es un conflicto de "carácter interno." Este impuesto de "soberania" consistía fundamentalmente en una soberanla del impuesto al patrimonio, que oto de "carácter interno." Este impuesto de "soberanla" consistía fundamentalmente en una sobretasa del impuesto al patrimonio, que oscilaria entre $1.0 \%$ y $4.0 \%$ para un capital imponible superior a 1 millón de colones.

Si bien el carácter intensivo y desestabilizador del rechazo empresarial parecía indicar que la incidencia de la relorma tribularia se agudizaria y concentraria en ese estrato, realmente el peso económico del gravamen serla insignilicante para el gran capital, tal como el análisis anterior lo demuestra. Esto lo reconocia el mismo gobierno y su partido. EI PDC senalaba que con la reforma tributaria sólo se esperaba aumentar la "contribución de los grandes propietarios en unos ciento cincuenta millones," es decir, un 5\% de los ingresos tributarios de 1986; por su lado, el presidente Duarte declaró que el impuesto de soberanla aportaria "apenas un $10 \%$ de los costos de la guerra durante 1986" y serviria "sobre todo para que puedan vivir con tranquilidad aquellos que tienen millones."53

El rechazo empresarial agudizaba la irreversible crisis financiera del gobierno. Según cifras oficiales, 1986 significo un incremento de $1,000 \mathrm{mi}-$ llones de colones en el presupueslo general de la nación, "herencia" legada al presupuesto de 1987 que se mantendría a los mismos niveles del afo anterior, es decir, alrededor de 3,500 millones de colones. Para el financiamiento de este gasto se esperaba contar con las recaudaciones adicionales que generaría la reforma tributaria y que optimistamente se eslimaban en unos 350 millones de colones; además, se esperarían donaciones superiores a $\mathbf{5 0 0}$ millones y para cubrir la brecha se recurrla a financiamiento externo por un monto de 600 millones de colones, 10 que significaria un incremento de $132 \%$ en este lipo de endeudamiento respecto a lo contratado en 1986. El défecit global (excluyendo donativos) proyeclado para 1987 alcanzaria 763 millones de colones, $26 \%$ superior al de 1986.

Ciertamente, la situación fiscal para 1987 sería peor que la planteada por las proyecciones oficiales, en parte como resultado de la "marcha atrás" del gobierno en la implementación de la reforma tribularia. Elec- 
tivamenle, en una "sesión de emergencia" convocada por los diputados del PDC el 20 de enero de 1987, se aprobaron las primeras moditicaciones al impuesto de "soberania" y dos dlas después se dejó sin efecto el aumento del impuesto a los cigarrillos. Posteriormente, el 12 de lebrero, el Ejeculivo presentó a la Asamblea Legislativa "importantes" reformas a la ley del impueslo sobre al renta y el patrimonio, aceplándose nuevamente algunas deducciones y rentas exentas que hablan sido suprimidas por la relorma tributaria y estableciendo que el patrimonio nelo imponible será calculado al valor real actual de los activos, medlante el "autovalúo que consigne el contribuyente," excluyéndose de su pago bienes tales como los bonos de la reforma agraria, viviendas, escuelas, etc. Asimismo, se modifica la disposición de gravar las uttlidades de sociedades que operan como subsidiarias de un "holding" y las de éste cuando la subsidiaria le traslada sus dividendos; esto se hace introduciendo la siguiente modificación: "las personas juridicas domicilladas tendrán derecho a un crédito contra su impuesto por las utlidades gravables recibidas de otra sociedad..."

La marcha atrás del gobierno en la implementación de la relorma tribularia condujo hasta la declaratoria de "inconstitucionalidad" del "impuesto de guerra," fallo emitido por la Corte Suprema de Justicia el 19 de febrero de 1987 esfumándose los 120 millones de colones que se esperaba recaudar con dicho impuesto. Un dla después, el Vice-Ministro de Hacienda senaló que la decisión de la Corte aumentarla el déficit tiscal en unos 600 millones de colones, ya que a esos 120 millones que dejarian de percibirse habrla que sumar la contracción esperada de $\mathbf{4 0 0}$ millones de colones en las recaudaciones del impuesto al café como resultado de la baja en los precios internacionales de ese grano..$^{54}$

Con las modificaciones hechas a la "reforma tributaria", solo se esperaba obtener de ella unos 60 millones en ingresos adicionales, con lo que el déficil global podrla alcanzar 1,000 millones de colones en 1987 es decir, el mayor délicit fiscal en toda la historia del pais y a un nivel verdaderamente explosivo.

El gran capital ha mostrado nuevamente su poder y su rechazo a participar, ni siquiera minimamente, en el financiamiento de la guerra; a pesar que con ésla se defienden fundamentalmente sus intereses. Todo indica que sus intenciones son las de continuar obteniendo las mayores ganancias mienlras se pueda, sin ceder un ápice en este cometido. El afán de lucro del gran capital y la ampliación y profundización de la crisis, conducen al gobierno al borde de la quiebra fiscal.

La dinámica explosiva de la crisis fiscal no solo ha tensionado las rigideces que enfrenla la Iribulación como fuente de financiamiento, también nos acerca aceleradamente a los límiles estructurales que enfrenta 
el financiamiento mediante emisión monelaria y endeudarniento externo. La deuda pública externa creció más de 3 veces entre 1979 y 1985; el servicio de esta deuda representa más del $40 \%$ de las divisas generadas por nuestras exportaciones y aún eslo a costa de continuas regeneraciones que difieren para el luturo inmedialo el mayor peso acumulado de este tipo de endeudamienlo. Sólo como resullado de la devolución la amortización de la deuda pública se duplicó, que aunado al pago de intereses absorbia el 19\% del presupuesto de 1986.55

Por olro lado, estudios realizados por el Ministro de Planificación señalan que la máxima recaudación posible mediante emisión monetaria se alcanzarla cuando la inflación llegue a un $60 \% ; 56$ a partir de ese nivel, incrementos adicionales de la oferta monetaria se traducirán cada vez en más inflación. Pero la emisión monetaria como insirumenlo de financiamiento público no sólo alcanza aceleradamente sus límites técnicoeconómicos; el acelerado deterioro de las condiciones de vida de la mayoria de salvadorenos, el agotamienilo político del gobierno y los niveles alcanzados por la organización y la lucha laboral, marcan los limiles políticos de ese instrumento tradicional de financiamiento público.

\section{A manera de conclusión}

A lo largo de esle esludio se han identificado y analizado los faciores generadores de la crisis fiscal en El Salvador, demostrándose que esta crisis es un resultado "natural" de las caraclerísticas estruclurales y de la dinámica de funcionamiento del aparato productivo. Cierlamente, la naturaleza agro-exportadora y dependiente de la luente fundamental de acumulación de capital en El Salvador, condicionó la vulnerabilidad del presupuesto público con respecto al sector externo; pero es el desarrollo y requerimienlos de la producción fabril, lo que define claramente y profundiza los factores generadores de la crisis fiscal, que entran en una dinámica expansiva e irreversible en la década del setenta, manifestándose en: el elevado ritmo de crecimiento del gasto público y su extrema subordinación a los requerimientos de la producción fabril, una estructura tributaria "benefactora" de la acumulación industrial, rígida y peligrosamente dependiente del comercio exterior; un délicit fiscal y un endeudamiento público crecientes.

Las debilidades y límites de la acumulación de capilal en EI Salvador genera una industria fuertemente subsidiada por el Estado, en donde el "intervencionismo estatal" se convierte en una necesidad del proceso mismo de valorización de capilal. Sin embargo, si bien ese decidido y creciente apoyo eslatal ha coadyuvado fuerlemente a la continuación del proceso de valorización los desequilibrios y límiles que enfrenla se prolundizan con la dinámica de funcionamiento del modelo y en la medida 
que se acelera la concentración, centralización y transnacionalización del capital. Todo ello se traduce en el agudizamienlo de la crisis estructural, en el agolamienlo del modelo y en un desequilibrio fiscal profundo e incontrolable.

La profundización de las dificultades y requerimienlos para la valorización del capilal y la expansión e inlensificación de la pobreza y el descontento popular, que desemboca en una guerra civil abierta desde los primeros años de la aclual década, se convierte en faclores que propagan y aceleran la crisis liscal, imprimiéndole una dinámica "explosiva" en la medida que se tiende a alcanzar rápidamente los límiles económicos y políticos del manejo presupueslario.

Las regideces estruclurales y la dinámica de la crisis le sefialan márgenes muy estrechos a los programas de política económica mediante los cuales se ha tratado de entrentar el desequilibrio fiscal en los últimos años. Más bien, eslos programas de corle monetarisla orlodoxo lienden a agravar la crisis, "exprimiendo" las fuenles tradicionales de financiamienlo público y alimentando la dinámica explosiva de la crisis.

Ciertamente, el modelo ha mostrado claramente su agotamienlo e incapacidad, no sólo para satisfacer las necesidades populares, sino también para mantener la dinámica misma del proceso de valorización y acumulación de capilal. La redilinición del modelo es una necesidad para el gran capilal y su readecuación en función de las mayorias populares es la única posibilidad de sobrevivencia para EI Salvador.

\section{NOTAS}

1. Para "disciplinar" a esta luerza de trabajo que habla sido liberada de la propiedad de medios de vida y que entrarla a lormar parte de una nueva lógica de producción y distribución, se crea una serie de medidas y aparalos policiales, entre los que se destacan: creación de la Ley contra la Vagancia en 1881, creación de la Policia Rural en 1884 y la Policía Montada entre 1889 y 1895. Además, el aparalo estatal provee la iniraestruetura básica $\theta$ incentivos para la expansión caletalera; en 1845 se inicia la ocnstrución de una carretera entre San Miguel y La Unión, y otra que relacionaria Acajutla-Sonsonate-Santa Ana; en 1853 se inicia el servicio marltimo regular entre La Libertad, Acajutla y La Unión, y $6 \theta$ lirma el primer conlrato comercial con los Estados Unidos; se conceden exceciones impositivas a los cafetaleros y se exime del servicio militar a los trabajadores de estas fincas.

2. Wilson, Everett A. "La crisis de integración nacional en El Salvador," en "El Salvador de 1840 a 1935." UCA editores, San Salvador. Pp. 178-180.

3. Los precios del calé cayeron de un nivel de $\$ 12.88 / q q$ en 1913 a $\$ 8.40 / q q$ en 1914 ; aún en 1921 el precio del całé no habla recuperado su nivel, alcanzando en ese año un precio de \$11.0/qq. Ver Wilson, Op. Cit. P. 168.

4. Wilson, Everelt. Op. Cit., P. 197.

5. Ibid, Pp. 200-202. 
6. Ver: Véjar, Rafael G. "El ascenso del militarismo en El Salvador." UCA Editores, San Salvador.

7. López, Carlos. "industralización y Urbanización en EI Salvador." UCA Editores, 1984.

8. Dada, Héctor H. "La economía de El Salvador y la integración centroaméricana (1945. 1960)." UCA Editores. San Salvador, P. 30.

9. Ibid.

10. Ibid. Pp. $38-55$

11. Ibid. P. 62

12. Fuente: CEPAL. Citado por Dada, Hóclor en Op. Cit. Pp. 47-48.

13. Dada, Hécior H., Op. cit. Pp. 48-49.

14. Fuente: Anuarios estadisticos. DIGESTIC. EI Salvador.

15. Galo Bonilla, A. "La concentración y centralización de capital en la industria manufacturera de El Salvador." Tesis de grado. Departamento de Economla, UCA. San Salvador. Anexos.

16 Villaherrera, S. y Martinez. M. "La inserción aclual de la economla salvadoreña en la economia mundial: La inversión extranjera directa como un mecanismo de inserción." Tesis de grado. Departamento de Economia, UCA. San Salvador, Anexos.

17. Ibid.

18 Galo Bonilla, A. Op. Cit. Anexos.

19. Ibid.

20 Ibid.

21. Ver: Moreno, C. y Chorro, M. "Acumulación industrial y polílica fiscal en El Salvador: 1964-1984. Un enloque Kaleckiano." Tesis de grado. Departamento de Economla, UCA. San Salvador.

22. Fuente: Proyectos elaborados por diferentes ministerios e instituciones autónomas. San Salvador.

23. SIECA. "Acla de la segunda reunión conjunta del consejo económico y monetario centroamericand." Marzo de 1986.

24. En 1952 se crea la "Ley de Fomento de Industria de Transformación;" en 1961, la "Ley de Fomento Industrial" $y$ el "Convenio Cenlroamericano de incentivos fiscales al desarrollo industrial" que se suscribió en 1962 y entró en vigencia a finales de al década.

25. El componente importado de la producción industrial salvadoreña en su conjunto, se amplla desde la decada del sesenta; asl, la proporción de la materia prima importada para la producción industrial en nuestro país, aumentó de $12 \%$ en 1961 a $46 \%$ en 1971. Pero sobresalen la industria quimica y melal-mecánica (ramas 35 y 38 ), que importan más del $80 \%$ de sus materias primas: mientras que la rama 32 (lextiles) y prineipalmente la rama 31 (alimentos, donde sobresalen la industria del calé) se nutren prelerentemente de malerias primas nacionales.

Fuente: "Memoria del segundo congreso de ingenierla," Tomo I, P. 365. Tomado de: Orellana, A. y Allaro, J. "Necesidades básicas y reactivación de la economla." Tesis de grado. Departamento de Economla, UCA San Salvador. Anexos.

26. Galo Bonilla, A., Op. cit. Anexos.

27. Villahererra, S. Op. Cit. Anexos.

28. Las ramas ejes o tradicionales son aquellas actividades en las que se tundamentó la acumulación industrial en la década del cincuenta y que han mantenido gran parte de la dinámica industrial en nuestro país. Hasta finales de la década del sesenta, estas ramas dedicadas a la producción de alimentos, bebidas, tabaco y textiles (ramas 31 y 32), hablan sido relativamente marginados de los "beneficios" de la inversión extranjera debido fundamentalmente a que eran consideradas como patrimonio exclusivo del capital oligárquico; pero la recesión industrial de finales del sesenta y las mayores necesidades teconológicas para "capturar" mercados fuera del área centroamericana. 
condujeron a una luerte apertura y penetración de capital extranjero en estas ramas tradicionales durante la década del selenla.

29. Ver: Departamento de Economla. "Dinámica y crisis de la economla dsalvadoreña." ECA, enero-febrero 1986. UCA, San Salvador.

30. Fuente: Ministerio de Hacienda "Informes complementarios constitucionales de le Hacienda Públice." El Salvador. Varios años.

31. Ibid.

32. Ibid

33. Fuente. Ministerio de Hacienda "Clasificación sectorial del gasto público"

34. Ibid.

35. Ibid.

36. Ibid.

37. FUSADES, "Análisis crltico de la polltica fiscal." San Salvador, P. 13.

38. Fuente: Ministerio de Hacienda. San Salvador.

39. Fuente: Ministerio de Hacienda. Departamento de Asuntos Industriales, citado en Campos, M. y Landaverde, M. "Los incentivos fiscales a la industria manulacturera como mecanismo estimulador de beneficios extraordinarios en una economla concentrada." Tesis de grado, Departamento de Economla, UCA. San Salvador.

40. Fuente: Ibid.

41. Fuente: Banco Central de Reserva. "Conferencias conmemorabivas del cincuente aniversario de hundación del banco." San Salvador.

42. Ibid.

43. Alvarado, J.A., "Análisis de la situación fiscal." Boletln de Ciencias Económicas y Sociales, enero-lebrero 1997. UCA. San Salvador. P. 69.

44. Ibid.

45. Ibid., P. 69.

46. FUSADES. "Opciones para financiar el déficit fiscal de 1987." San Salvador. P.6.

47. Estadlsticas del BCR. San Salvador.

48. PDC. "la relorma tributaria, justicia para el pueblo." La prensa Grálica, 19 de diciembre de 1986. San Salvador. P. 57.

49. Ibid.

50. FUSADES. "Análisis critico de la pollíca fiscal. San Salvador, Diciembre de 1986.

51. Ibid.

52. Ibid.

53. Véase proceso No. 276. "Alternativas fiscales para financiar la guerra." UCA. San Salvador. P. 9.

54. Ibid. P. 10

55. Alvarado. J.A. Op. Cit., P. 72

56. MIPLAN. Documento de Trabajo. San Salvador. 